\title{
Distribution-free Phase II Mann-Whitney Control Charts with Runs-rules
}
J.C. Malela-Majika ${ }^{\mathrm{a}}$
S. Chakraborti ${ }^{\mathrm{b}, \mathrm{a}}$
M.A. Graham ${ }^{\mathrm{a}, \mathrm{c}}$
jcmalela2005@yahoo.fr
schakrab@cba.ua.edu
marien.graham@up.ac.za

\begin{abstract}
The addition of runs-rules has been recommended to improve the performance of classical, normal theory Shewhart-type control charts, for detecting small to moderate size shifts. In this paper, we consider adding both standard and improved runs-rules to enhance the performance of the distribution-free Phase II Shewhart-type chart based on the well-known Mann-Whitney statistic proposed by Chakraborti and Van de Wiel [1]. Standard runs-rules are typically of the form $w$-of- $(w+v)$ with $w>1$ and $v \geq 0$ and the improved runs-rules scheme is a combination of the classical $1-o f-1$ runs-rule and the $w$-of- $(w+v)$ runs-rules. The improved scheme improves the performance of the charts in detecting larger shifts while maintaining its performance in detecting small to moderate shifts. The in-control and out-of-control performance of the proposed runs-rules enhanced distribution-free charts are examined through extensive simulations. It is seen that the proposed charts have attractive performance compared to some competing charts, and are better in many cases. An illustrative example is provided, along with a summary and conclusions.
\end{abstract}

Keywords: Case U, Improved Runs-rules, Mann-Whitney test, Shewhart-type chart.

\section{Introduction}

During the last decade, distribution-free (nonparametric) control charts have become increasingly popular. These charts are useful when the underlying distribution is not known and have been shown to perform well compared to their normal theory counterparts. Nonparametric control charts are often designed by adapting corresponding nonparametric hypothesis tests. It may be noted that remarkably, even when the underlying distribution is normal, the efficiency of some nonparametric tests, relative to their normal theory counterparts, can be as high as 0.955 (see e.g. Gibbons and Chakraborti [2] page 218). For some other heavy-tailed and skewed distributions, the efficiency can be 1.0 or even higher. It may be argued that nonparametric methods will be 'less efficient' than their parametric counterparts when one has a complete

\footnotetext{
${ }^{\text {a }}$ Department of Statistics, University of Pretoria, South Africa

${ }^{\mathrm{b}}$ Department of Information Systems, Statistics and Management Science, University of Alabama, Tuscaloosa, AL 35487, U.S.A.

c Corresponding author: Dr MA Graham, +27 (0) 124204621 (phone), +27 (0) 124205175 (fax), marien.graham@up.ac.za (email)
} 
knowledge of the process distribution for which that parametric method was specifically designed. However, the reality is that such information is seldom, if ever, available in practice.

Over the last decade or so, many nonparametric control charts have been proposed in Statistical Process Control (SPC). Their advantages are listed in Chakraborti et al. [12] and are as follows: (i) easy to implement, i.e. simplicity; (ii) no need to assume a particular parametric distribution for the underlying process; (iii) the IC run-length distribution is the same for all continuous distributions; (iv) more robust and outlier resistant; (v) more efficient in detecting changes when the true distribution is markedly non-normal, particularly with heavier tails, and (vi) no need to estimate the variance to set up charts for the location parameter. For a thorough account on nonparametric control chart literature, including some recent developments, the reader is referred to Chakraborti et al. [12], Chakraborti and Graham [13] and Chakraborti et al. [14].

Among the many nonparametric control charts, the Mann-Whitney (hereafter MW) control chart, based on the well-known Mann-Whitney test (see Gibbons and Chakraborti [2]) is one of the most powerful due to its in-control (IC) robustness and good out-of-control (OOC) performance. Park and Reynolds [3] considered Shewhart-type charts for monitoring the location parameter of a continuous process in where the process parameters are unknown, and the MW chart based on the MW-Wilcoxon statistic is one of their special cases. However, they only considered properties of this chart when the reference sample size approaches infinity. Chakraborti and van de Wiel [1] considered the Shewhart-type MW chart for a finite reference sample size and studied its properties in more details. They showed that, in many cases, the MW chart performs better than the competing charts no matter the nature of the underlying process distribution. Among other uses of the MW statistic, a change-point formulation was investigated by Zhou et al. [4]. Li et al. [5] proposed a nonparametric cumulative sum (CUSUM) chart and a nonparametric exponentially weighted moving average (EWMA) control chart based on the Wilcoxon rank-sum (WRS) statistic $\mathrm{W}$, respectively, with the $\mathrm{W}$ statistic being equivalent to the MW statistic.

In many settings, however, the Shewhart-type charts remain the most popular due to their operational simplicity and global performance. In order to improve their performance in detecting small to moderate shifts, the addition of runs-type signaling rules (in short, runs-rules) has been recommended for the normal theory Shewhart-type charts. The use of runs-rules with 
the Shewhart $\bar{X}$ chart, to increase its sensitivity in detecting small shifts, has been studied by Champ and Woodall [6]. These runs-rules are typically of the form $w$-of-(w+v) with $w>1$ and $v$ $\geq 0$. More recently, Klein [7] proposed runs-rules with $w=2$ and $v=0$ and 1, respectively, leading to the well-known 2-of-2 and 2-of-3 runs-rules. Khoo and Ariffin [8] proposed an improved runs-rules scheme which is a combination of the classical 1-of-1 runs-rule and the $w$ $o f-(w+v)$ runs-rules. Koutras et al. [9] reviewed the well-known Shewhart-type charts supplemented with additional rules based on the theory of runs and scans. A class of Phase II nonparametric charts based on precedence statistics with runs-rules was proposed by Chakraborti et al. [10]. Zhang and Castagliola [11] investigated the runs-rules based Shewhart $\bar{X}$ charts when process parameters are unknown. However, to date, runs-rules have not been applied to the Shewhart-type MW chart studied by Chakraborti and Van de Wiel [1]. In this paper we fill this gap by proposing and studying a class of nonparametric control charts with runs-rules where the charting statistic is based on the MW test statistic.

The performance of control charts depends on many factors such as: the type of chart, the nature of the underlying process distribution, the charting statistic, etc. In order to implement a control chart we need at least one sample observed on a particular quality characteristic from which the charting statistic is calculated. Nonparametric charting statistics are mostly based on two-sample tests. This is for Case U where the process parameter(s) is/are unknown. The MW chart is based on the MW test, which is one of the most popular nonparametric tests for light tailed distributions (see Gibbons and Chakraborti [2] page 261). Thus, the MW control chart is expected to be more powerful than many other control charts in this case. We describe the details in the next section.

\section{Mann-Whitney control chart}

\subsection{MW charting statistics}

These charts are to monitor the location parameter in the unknown parameter case (socalled Case U) where a reference sample is assumed to be available after a Phase I analysis. Assume that a reference sample of size $m$, say, $X_{1}, X_{2}, \ldots, X_{m}$, is available from an IC process with an unknown continuous cdf $F(x)$. Let $Y_{1}^{h}, Y_{2}^{h}, \ldots, Y_{n}^{h}, h=1,2, \ldots$, denote the $h^{\text {th }}$ test sample of size $n_{h}, n_{h}=n \forall h$, since we are assuming that the Phase II samples are all of the same size. Let $G^{h}(y)$ denote the cdf of the distribution of the $h^{\text {th }}$ Phase II sample and let $G^{h}(y)=G(y)$ $\forall h$, since the Phase II samples are all assumed to be identically distributed. The process is IC in 
Phase II when $G=F$. Typically, the location model is assumed, that is $G(t)=F(t-\delta)$, for all $t$, where $\delta$ is the location difference (or shift in the location parameter). In that case the process is IC when $\delta=0$.

The MW charting statistic $M_{X Y}$ represents the total number of $\left(X_{i}, Y_{j}\right)$ pairs where the $Y$ observation (Phase II sample) is strictly greater than the $X$-observation (Phase I sample). This is defined by

$$
M_{X Y}=\sum_{i=1}^{m} \sum_{j=1}^{n} I\left(Y_{j}>X_{i}\right)
$$

where $I\left(Y_{j}>X_{i}\right)$ is an indicator function defined as follows

$$
I\left(Y_{j}>X_{i}\right)=\left\{\begin{array}{ll}
1 & \text { if } Y_{j}>X_{i} \\
0 & \text { if } Y_{j} \leq X_{i}
\end{array} .\right.
$$

Note that there are $m n\left(X_{i}, Y_{j}\right)$ pairs for each Phase II sample, therefore, $0 \leq M_{X Y} \leq m n$. For the two most extreme orderings every $x$ precedes every $y$ (so that $M_{X Y}=0$ ) and every $y$ precedes every $x$ (so that $M_{X Y}=m n$ ). The proposed charting statistics are given by, $M_{X Y}^{1}, M_{X Y}^{2}, \ldots$.

\subsection{Control limits}

When implementing the MW control chart, we plot the charting statistics $M_{X Y}^{h}(h=$ $1,2, \ldots$ ) for each test sample $h$. The classical 1 -of- 1 MW chart studied by Chakraborti and Van de Wiel [1] signals if the charting statistic falls on or above the upper control limit (UCL) or if the charting statistic falls on or below the lower control limit $(L C L)$. Since the IC distribution of the charting statistic $M_{X Y}$ is symmetric about $\frac{m n}{2}$, the control limits are taken to be symmetrical. By means of the symmetry property (see Gibbons and Chakraborti [2] page 264), we have $P\left(M_{X Y}=\right.$ $a)=P\left(M_{X Y}=m n-a\right)$ for $0 \leq a \leq m n$ when the process is IC. Thus we set $L C L=m n-$ $U C L$. If the charting statistic falls between the control limits, that is, $L C L<M_{X Y}<U C L$, the process is declared to be IC, otherwise the process is declared OOC.

\subsection{Run-length $(N)$ and Average Run-Length $(A R L)$}

The reader is referred to Chakraborti and Van de Wiel [1] for more details. Here we only give some key concepts. Let $p_{G}(\underline{x})=P_{G}\left(M_{\underline{x} Y} \leq m n-U C L\right)+P_{G}\left(M_{\underline{x} Y} \geq U C L\right)$ denotes the probability of a signal with any test (Phase II) sample, given the reference sample $\left(X_{1}, X_{2}, \ldots, X_{m}\right)=\left(x_{1}, x_{2}, \ldots, x_{m}\right)$ denoted $\underline{X}=\underline{x}$. Therefore, the conditional run-length distribution is given by

$$
P(N=k \mid \underline{X}=\underline{x})=\left(1-p_{G}(\underline{x})\right)^{k-1}\left(p_{G}(\underline{x})\right) \text { for } k=1,2, \ldots .
$$


Let $N$ denote the run-length random variable for the chart given the reference sample $\underline{X}=\underline{x} . N$ is geometrically distributed with parameter $p_{G}(\underline{x})$. Consequently, the conditional $A R L$ is given by

$$
C A R L=E_{G}(N \mid \underline{X}=\underline{x})=\frac{1}{p_{G}(\underline{x})} .
$$

On the other hand, using Expression (4) and integrating over the distributions of the reference samples, the unconditional $A R L$ is found to be

$$
U A R L=E_{F}\left[E_{G}(N \mid \underline{X}=\underline{x})\right]=E_{F}\left(\frac{1}{p_{G}(\underline{x})}\right)=\int_{-\infty}^{\infty} \ldots \int_{-\infty}^{\infty} \frac{1}{p_{G}(\underline{x})} d F\left(x_{2}\right) \ldots d F\left(x_{m}\right) .
$$

Note that Expression (5) is an $m$-dimensional integral, moreover we do not have an exact formula for the probability of a signal. Accordingly it is difficult and time-consuming to estimate the unconditional $A R L$ using this formula. To overcome these problems, Chakraborti and Van de Wiel [1] proposed using Monte Carlo simulations or a Markov chain approach. Using a Markov chain approach, one has to do matrix inversion which can be very time consuming, particularly for large matrices. For this reason, in this paper we used Monte Carlo simulation with 10000 simulations.

\subsubsection{In-Control $A R L$}

In Phase II, the process is IC when $F=G$. Therefore, the unconditional IC $A R L$ is found by substituting $G=F$ into Expression (5).

$$
U A R L_{0}=\int_{-\infty}^{\infty} \ldots \int_{-\infty}^{\infty} \frac{1}{p_{F}(\underline{x})} d F\left(x_{2}\right) \ldots d F\left(x_{m}\right) .
$$

Expression (6) can be re-written, using the probability integral transformation, as:

$$
U A R L_{0}=\int_{-\infty}^{\infty} \ldots \int_{-\infty}^{\infty} \frac{1}{p_{U}(\underline{u})} d u_{1} \ldots d u_{m}
$$

For more details the reader is referred to Gibbons and Chakraborti [2] page 39. The subscript $U$ refers to the $U(0,1)$ distribution and $p_{U}(\underline{u})$ is the conditional probability of a signal at any test sample, given the reference sample, when the process is IC.

\subsubsection{Out-of-Control $A R L$}

In the OOC case, $G \neq F$, the unconditional OOC $A R L$ is given by

$$
U A R L_{\delta}=\int_{-\infty}^{\infty} \cdots \int_{-\infty}^{\infty} \frac{1}{p_{G}(\underline{x})} d F\left(x_{2}\right) \ldots d F\left(x_{m}\right),
$$

where $\delta(\neq 0)$ represents the shift between $F$ and $G$, in their location parameters. Thus, in order to implement the MW chart we have to calculate the $U A R L_{0}$ and in order to evaluate the performance of the MW chart we have to evaluate the $U A R L_{\delta}$. Using a similar argument as 
earlier, it will not be easy to calculate these using Expressions (7) and (8) and, accordingly, we use Monte Carlo simulations. This will be explained in more detail later on.

\section{Runs-Rules and Enhancements of the MW Chart}

The classical 1 -of- 1 rule, i.e. when only one charting statistic is considered, as considered in Chakraborti and Van de Wiel [1], will be denoted by $\mathrm{RR}_{1-o f-1}$ from this point forward. When considering the 2-of-2 runs-rule, which gives a signal when two consecutive charting statistics plot OOC, there is a distinction in the literature between the 2-of-2 runs-rules proposed by Klein [7], denoted KL (see (a) below), and the 2-of-2 runs-rules proposed by Derman and Ross [15], denoted DR (see (b) below). The formal definitions are given as follows.

(a) Two consecutive points both fall on or above the $U C L$ or both fall on or below the $L C L$ (KL scheme).

(b) Two consecutive points (i) both fall on or above the $U C L$ or, (ii) both fall on or below the $L C L$ or, (iii) one falls on or above the $U C L$ and the next one falls on or below the $L C L$ or, (iv) one falls on or below the $L C L$ and the next falls on or above the $U C L$ (DR scheme).

Chakraborti et al. [10] showed that the KL scheme outperforms the DR scheme and, accordingly, only the KL scheme is considered in this paper. The 2-of-2 KL runs-rule will be denoted by $\mathrm{RR}_{2}$ of-2 from this point forward. The improved runs-rules of Khoo and Ariffin [8], which is a combination of the classical 1-of-1 runs-rule and the 2-of-2 runs-rule, will be denoted by $\mathrm{IRR}_{2-o f-}$ 2. These rules are described below.

\subsection{The $\mathbf{R R}_{1-o f-1}$, the $\mathbf{R R}_{2-o f-2}$ and the $\mathbf{I R R}_{2-o f-2} \mathrm{MW}$ control chart \\ Rule 1: $\mathbf{R R}_{\text {1-of-1 }}$}

The $\mathrm{RR}_{1-o f-1}$ scheme signals when the charting statistic $M_{X Y}$ plots on or above the $U C L_{1}$ or plots on or below the $L C L_{1}$. The subscript refers to the rule number. The use of subscripts is necessary in order to emphasize the fact that the values of the control limits for the three rules are not equal.

\section{Rule 2: $\mathbf{R R}_{2-o f-2}$}

The $\mathrm{RR}_{2-o f-2}$ scheme signals when two consecutive charting statistics, say $M_{X Y}^{h}$ and $M_{X Y}^{h+1}$ for $h=1,2, \ldots$, both plot on or above the $U C L_{2}$ or both plot on or below the $L C L_{2}$.

\section{Rule 3: IRR 2 -of-2}

For the $\mathrm{IRR}_{2-o f-2}$ scheme some warning limits are introduced, namely, the $U W L_{3}$ and the $L W L_{3}$, where $L C L_{3}<L W L_{3}<U W L_{3}<U C L_{3}$. The improved runs-rules signal when one charting 
statistic $M_{X Y}$ plots on or above $U C L_{3}$ or plots on or below $L C L_{3}$ or when two consecutive charting statistics, say $M_{X Y}^{h}$ and $M_{X Y}^{h+1}$, for $h=1,2, \ldots$, plot between $\left[U W L_{3}, U C L_{3}\right)$ or between $\left(L C L_{3}, L W L_{3}\right]$.

\section{Implementation of the MW control chart with runs-rules}

\subsection{Monte Carlo simulation}

The steps for determining the chart constants (control limits) and for obtaining the characteristics of the run-length distribution are given for the $\mathrm{RR}_{2-o f-2}$ scheme; it can easily be amended to include warning limits for the $\mathrm{IRR}_{2-o f-2}$ scheme.

Step 1: Specify two distributions for generating a Phase I and Phase II sample, respectively. For the IC case, the two distributions are identical (we say that the shift equals zero $(\delta=0))$. For the OOC case, the distribution for the Phase II sample is taken to be the same form as that for the Phase I sample, but with a shift in the location parameter in units of the population standard deviation. For example, the Phase I sample may be drawn from a normal distribution with mean 0 and standard deviation 1 , whereas, in the OOC case, the Phase II sample may be drawn from a normal distribution with mean $\neq 0$ and standard deviation 1 (we say that the shift in the location (mean), $\delta$, is not equal to zero $(\delta \neq 0))$.

Step 2: $\quad$ Specify the Phase I reference sample size $(m)$, the Phase II test sample size $(n)$, the number of simulations $(r)$ and the parameter(s) of the distribution. For example, suppose we have a reference sample of size 100 with mean 0 and standard deviation 1 , a test sample of size 5 with mean $\delta$ and standard deviation 1 and 10000 simulations are used, then $\delta=0(0.25) 3, m=100, n=5$ and $r=10000$. In the IC case $\delta=0$ while in the OOC case $\delta \neq 0$.

Step 3: The $U C L_{2}$ can take on any integer value in the range $\left[\frac{m n}{2}+1, m n-1\right]$. Thus, we vary $U C L_{2}$ from the smallest integer in the specified range to the largest integer in increments of 1 . In our example, with $m=100$ and $n=5$, the $U C L_{2}$ can take on any integer value in the range [251,499].

Step 4: Randomly generate a Phase I sample from a distribution, such as the $N(0,1)$ distribution. 
Step 5: For any given value of the $U C L_{2}$, specified in Step 3, calculate its corresponding $L C L_{2}=m n-U C L_{2}$. For example, say $U C L_{2}=300$, then we have $L C L_{2}=(100)(5)-$ $300=200$ for $m=100$ and $n=5$.

Step 6: Randomly generate a Phase II test sample from the same distribution. Calculate the first MW charting statistic (point) using Expression (1) and compare it to the control limits obtained in Step 5. If this first point plots between the control limits we have to generate the next test sample, calculate the next point and compare it to the control limits obtained in Step 5. Continue this process until a point plots beyond the control limits. Once we get such a point, we again generate a new test sample and calculate the new point. The chart signals if both charting statistics (the previous and the new one) plot on or above (below) the $U C L_{2}\left(L C L_{2}\right)$. If this does not happen, then continue with the process until the chart signals for the first time and record the number of subgroups needed to get to that stage. In our example, after generating the first Phase II test sample, the first charting statistic $\left(M_{X Y}^{1}\right)$ is calculated. This is compared to the control limits $L C L_{2}=200$ and $U C L_{2}=300$. If $M_{X Y}^{1} \leq 200$ or $M_{X Y}^{1} \geq 300$ we generate a second Phase II test sample and calculate a second charting statistic $\left(M_{X Y}^{2}\right)$. The latter is compared to the control limits and, if it is also less than or equal to $200\left(M_{X Y}^{2} \leq 200\right)$ or if it is also greater than or equal to $300\left(M_{X Y}^{2} \geq 300\right)$ the chart signals. The runlength will equal two because we needed two Phase II test samples in order to get a signal. On the other hand, assume that the second charting statistic plotted between the control limits. Then, we need to generate new Phase II test samples until we get a charting statistic less than (greater than) or equal to 200 (300). Once we obtain such a charting statistic, generate the next test sample and calculate the corresponding charting statistic. Compare the new charting statistic to 200 and 300. Then, the chart signals if the new charting statistic plots below (above) the 200 (300) as well. Record the number of subgroups needed until we get a signal for the first time. This number represents one value of the run-length distribution.

Step 7: Repeat Step 6 a total of $r$ times.

Step 8: Once the run-length values are obtained, calculate

$$
A R L=\frac{1}{r} \sum_{i=1}^{r} R L_{i}
$$


Step 9: Record the $L C L_{2}$ and the $U C L_{2}$ values next to the $A R L$ value (for $\delta=0$ this will be the IC $A R L)$.

Step 10: Repeat Steps 5 to 9 until all the values of $U C L_{2}$ allocated in Step 3 are considered.

Step 11: Select the control limits for which the IC $A R L$ is closest to the nominal value of 500.

Step 12: Repeat Steps 4 to 8 using the control limits found in Step 11 by varying the shift $\delta=$ $0(0.25) 3$ where $\delta=0$ provides IC values and $\delta \neq 0$ provides OOC values. Record the IC and OOC $A R L$ values.

Some illustrative examples are given below.

\section{Example 1}

For Rule 1, the $\mathrm{RR}_{1-o f-1}$ scheme, with $(m, n)=(20,5)$, the attained $A R L_{0}=426.77$ for $U C L_{1}=87$ and $L C L_{1}=20(5)-87=13$. For a different combination of $m$ and $n$, say $(m, n)=$ $(100,5)$, the attained $A R L_{0}=499.36$ for $U C L_{1}=436$ so that $L C L_{1}=(100)(5)-436=64$.

\section{Example 2}

For Rule 2, the $\mathrm{RR}_{2 \text {-of-2 }}$ scheme, with $(m, n)=(20,5)$, the attained $A R L_{0}=431.07$ for $U C L_{2}=75$ and $L C L_{2}=20(5)-75=25$. For a different combination of $m$ and $n$, say $(m, n)=$ $(100,5)$, the attained $A R L_{0}=508.42$ for $U C L_{2}=373$ so that $L C L_{2}=(100)(5)-373=127$.

From Examples 1 and 2 it can be seen that, as the size of the reference sample $(\mathrm{m})$ increases, the attained $A R L_{0}$ values tend to get closer to the nominal desired value of 500, i.e. the charts perform better, as expected nominally, for larger values of $m$.

\section{Example 3}

For Rule 3, the $\operatorname{IRR}_{2-o f-2}$ scheme, with $(m, n)=(500,5)$, the attained $A R L_{0}=496.32$ for $L C L_{3}=650, L W L_{3}=326, U W L_{3}=1850$ and $U C L_{3}=2174$.

Table 1 presents the chart constants (or control limits) and the corresponding attained $A R L_{0}$ values for different values of $m$ and $n$, for the $\mathrm{RR}_{1-\text { of- } 1}$, the $\mathrm{RR}_{2 \text {-of-2 }}$ and the $\mathrm{IRR}_{2 \text {-of-2 }}$ schemes, respectively. 
Table 1. Control limits and attained $A R L_{0}$ values for the three rules, the $\mathrm{RR}_{1-o f-1}$, the $\mathrm{RR}_{2-o f-2}$ and the $\mathrm{IRR}_{2-o f-2}$ schemes, for the Shewhart MW chart for different values of $m$ and $n$.

\begin{tabular}{|c|c|c|c|c|c|c|c|c|c|c|c|c|}
\hline \multicolumn{2}{|c|}{ Schemes } & \multicolumn{3}{|c|}{$R R_{1-o f-1}$} & \multicolumn{3}{|c|}{$R R_{2-o f-2}$} & \multicolumn{5}{|c|}{$I R R_{2-o f-2}$} \\
\hline$m$ & $n$ & $L C L_{1}$ & $U C L_{1}$ & $\begin{array}{c}\text { Attained } \\
A R L_{0}\end{array}$ & $L C L_{2}$ & $U C L_{2}$ & $\begin{array}{c}\text { Attained } \\
A R L_{0}\end{array}$ & $L C L_{3}$ & $L W L_{3}$ & $U W L_{3}$ & $U C L_{3}$ & $\begin{array}{c}\text { Attained } \\
A R L_{0}\end{array}$ \\
\hline \multirow{3}{*}{20} & 5 & 13 & 87 & 426.77 & 25 & 75 & 431.07 & 13 & 25 & 75 & 87 & 454.06 \\
\hline & 10 & 44 & 156 & 525.16 & 63 & 137 & 472.80 & 44 & 63 & 137 & 156 & 492.38 \\
\hline & 25 & 159 & 341 & 463.00 & 189 & 311 & 494.36 & 159 & 189 & 311 & 341 & 476.43 \\
\hline \multirow{3}{*}{25} & 5 & 16 & 109 & 478.43 & 31 & 94 & 487.70 & 16 & 31 & 94 & 109 & 486.14 \\
\hline & 10 & 55 & 195 & 487.63 & 79 & 171 & 511.22 & 55 & 79 & 171 & 195 & 506.72 \\
\hline & 25 & 196 & 429 & 472.18 & 237 & 388 & 505.74 & 196 & 237 & 388 & 429 & 507.18 \\
\hline \multirow{3}{*}{50} & 5 & 32 & 218 & 472.55 & 63 & 187 & 481.01 & 32 & 63 & 187 & 218 & 497.03 \\
\hline & 10 & 110 & 390 & 491.82 & 159 & 341 & 507.40 & 110 & 159 & 341 & 390 & 508.95 \\
\hline & 25 & 391 & 859 & 497.17 & 476 & 774 & 524.82 & 391 & 476 & 774 & 859 & 513.61 \\
\hline \multirow{3}{*}{75} & 5 & 47 & 328 & 508.73 & 95 & 280 & 512.29 & 47 & 95 & 280 & 328 & 513.17 \\
\hline & 10 & 167 & 583 & 506.96 & 241 & 509 & 509.73 & 167 & 241 & 509 & 583 & 508.30 \\
\hline & 25 & 590 & 1285 & 528.43 & 716 & 1159 & 523.58 & 590 & 716 & 1159 & 1285 & 510.07 \\
\hline \multirow{3}{*}{100} & 5 & 64 & 436 & 499.36 & 127 & 373 & 508.42 & 64 & 127 & 373 & 436 & 498.86 \\
\hline & 10 & 224 & 776 & 492.95 & 323 & 677 & 484.23 & 224 & 323 & 677 & 776 & 493.56 \\
\hline & 25 & 793 & 1707 & 501.51 & 960 & 1540 & 504.14 & 793 & 960 & 1540 & 1707 & 509.87 \\
\hline \multirow{3}{*}{125} & 5 & 80 & 545 & 492.68 & 160 & 465 & 499.92 & 80 & 160 & 465 & 545 & 496.09 \\
\hline & 10 & 279 & 971 & 503.86 & 405 & 845 & 483.67 & 279 & 405 & 845 & 971 & 504.56 \\
\hline & 25 & 992 & 2133 & 505.06 & 1204 & 1921 & 511.54 & 992 & 1204 & 1921 & 9133 & 510.64 \\
\hline \multirow{3}{*}{150} & 5 & 97 & 653 & 489.83 & 192 & 558 & 501.33 & 97 & 192 & 558 & 653 & 503.40 \\
\hline & 10 & 332 & 1168 & 502.40 & 486 & 1014 & 507.28 & 332 & 486 & 1014 & 1168 & 516.01 \\
\hline & 25 & 1190 & 2560 & 510.12 & 1443 & 2307 & 502.33 & 1190 & 1443 & 2307 & 2560 & 513.26 \\
\hline \multirow{3}{*}{200} & 5 & 130 & 870 & 512.44 & 257 & 743 & 504.73 & 130 & 257 & 743 & 870 & 503.58 \\
\hline & 10 & 446 & 1554 & 498.33 & 650 & 1350 & 500.61 & 446 & 650 & 1350 & 1554 & 505.26 \\
\hline & 25 & 1595 & 3405 & 501.76 & 1934 & 3066 & 505.70 & 1595 & 1934 & 3066 & 3405 & 518.14 \\
\hline \multirow{3}{*}{250} & 5 & 161 & 1089 & 515.13 & 323 & 927 & 501.74 & 161 & 323 & 927 & 1089 & 509.84 \\
\hline & 10 & 559 & 1941 & 521.56 & 819 & 1681 & 500.02 & 559 & 819 & 1681 & 1941 & 506.71 \\
\hline & 25 & 1970 & 4550 & 513.52 & 2423 & 3827 & 484.23 & 1970 & 2423 & 3827 & 4550 & 488.16 \\
\hline \multirow{3}{*}{500} & 5 & 326 & 2174 & 498.20 & 650 & 1850 & 493.10 & 326 & 650 & 1850 & 2174 & 500.21 \\
\hline & 10 & 1125 & 3875 & 501.50 & 1648 & 3352 & 491.83 & 1125 & 1648 & 3352 & 3875 & 503.04 \\
\hline & 25 & 4016 & 8484 & 492.46 & 4855 & 7645 & 519.89 & 4016 & 4855 & 7645 & 8484 & 507.05 \\
\hline
\end{tabular}


In Section 5 a performance comparison among the proposed runs-rules enhanced MW charts is done. We also include, in the comparison study, the distribution-free precedence charts proposed by Chakraborti et al. [10]. Note that although these authors considered the $\mathrm{RR}_{2 \text {-of-2 }}$ scheme, they did not consider the improved runs-rules and, accordingly, for the performance comparison we used the improved precedence chart proposed by Malela-Majika et al. [16].

Since obtaining the control limits is often time-consuming, we propose an approximation using regression, fitting a straight line between the Phase I sample size (the explanatory variable) and the upper control limit (the dependent variable). For example, with the data at our disposal for Rule 2, the $\mathrm{RR}_{2-o f-2}$ scheme, for the Shewhart MW chart (see Table 1, first and seventh columns for $n=5$ ), the least squares regression line is given by $\widehat{U C L_{2}}=2.6682868+$ $3.7000365 m$ and hence $\widehat{L C L_{2}}=m n-\widehat{U C L}_{2}$ where $\widehat{L C L_{2}}$ and $\widehat{U C L}_{2}$ denote the estimated lower and upper control limits, respectively. Similarly, for Rule 1, the $\mathrm{RR}_{1-o f-1}$ scheme, for the Shewhart MW chart (see Table 1, first and fourth columns for $n=5$ ) the fitted line is given by $\widehat{U C L_{1}}=0.908363+4.349375 m$ and $\widehat{L C L_{1}}=m n-\widehat{U C L_{1}}$. For the $\mathrm{IRR}_{2-o f-2}$ scheme, for the Shewhart MW chart (see Table 1), the estimated least squares regression lines for the upper warning and upper control limits are respectively given by $\widehat{U W L}_{3}=2.6682868+3.7000365 \mathrm{~m}$ and $\widehat{U C L}_{3}=0.908363+4.349375 m$ where $\widehat{L W L}_{3}=m n-\widehat{U W L}_{3}$ and $\widehat{L C L}_{3}=m n-\widehat{U C L}_{3}$. The regression approach seems to provide good approximations that can be used in practice, at least as a starting point. For instance, for $m=20$ and $n=5$ we find $\widehat{U C L}_{2}=76.67$ for the $\mathrm{RR}_{2-o f-2}$ scheme for the Shewhart MW chart. This value is close to the value 75 which was found using 10000 Monte Carlo simulations (see Table 1).

\subsection{Performance of the charts}

\subsubsection{The in-control $A R L$ robustness}

One of the important appealing properties of a nonparametric control chart is its IC robustness property which means that the IC run-length distribution does not depend on the underlying process distribution. We study this property here in an extensive simulation study using a wide collection of continuous distributions, including non-normal distributions, light and heavy-tailed distributions, symmetric and asymmetric distributions, uni-modal, bi-modal distributions as well as some positively skewed distributions. Note that, wherever necessary, all distributions have been shifted and scaled such that the mean / median equals 0 and the standard 
deviation equals 1 , so that the results are easily comparable across the distributions. Specifically, the distributions considered in the study are:

i. The standard normal distribution, $N(0,1)$.

ii. The Student's $t$-distribution, $t(v)$, with degrees of freedom $v=4$ and 8 , respectively, which is symmetric but with heavier tails than the Normal.

iii. The gamma distribution, $\operatorname{GAM}(\alpha, \beta)$, with parameters $(\alpha, \beta)=(1,1)$, is the

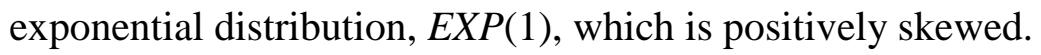

iv. The Laplace (or double exponential) distribution, $D E(0,1)$ which is symmetric but with a different tail behavior than the normal.

v. The $\log$-normal distribution, $\log N(0,1)$, which is a heavy-tailed distribution.

vi. The uniform distribution, $U(0,1)$, acknowledged as to be symmetric.

The attained $A R L_{0}$ values for the proposed charts, for these distributions, are shown in Table 2.

Table 2. Attained $A R L_{0}$ values for the $\mathrm{RR}_{1-o f-1}, \mathrm{RR}_{2-o f-2}$ and $\mathrm{IRR}_{2-o f-2} \mathrm{MW}$ Shewhart charts with $L C L_{1}=L C L_{3}=326, U C L_{1}=U C L_{3}=2174, L C L_{2}=L W L_{3}=650, U C L_{2}=U W L_{3}=1850$ when $m=500$ and $n=5$

\begin{tabular}{|l|c|c|c|}
\hline \multirow{2}{*}{ Distribution } & \multicolumn{3}{|c|}{$A R L_{0}$} \\
\cline { 2 - 4 } & $\mathrm{RR}_{\text {1-of- } 1}$ & $\mathrm{RR}_{2 \text {-of-2 }}$ & $\mathrm{IRR}_{\text {2-of-2 }}$ \\
\hline$N(0,1)$ & 498.46 & 493.10 & 500.21 \\
\hline$D E(0,1)$ & 501.74 & 494.72 & 484.70 \\
\hline$U(0,1)$ & 495.56 & 499.27 & 498.37 \\
\hline $\log N(0,1)$ & 488.86 & 492.17 & 507.58 \\
\hline$G A M(1,1)$ & 500.12 & 498.27 & 496.97 \\
\hline$t(4)$ & 504.10 & 493.27 & 488.58 \\
\hline$t(8)$ & 498.83 & 497.28 & 492.46 \\
\hline
\end{tabular}

From Table 2 it can be seen that, as expected, for every continuous distribution under consideration, the IC characteristics are almost equal; the difference between the values can be explained by simulation error. In practice we keep this error as small as possible (less than 10 percent of the nominal value of the $A R L)$.

\subsubsection{In-control and Out-of-control $A R L$}

When using the $A R L$ as the performance metric it is desirable to have a large attained $A R L_{0}$ and a small $A R L_{\delta}$. The $A R L$ can be calculated using Expression (9) by means of Monte Carlo simulations. However, since the run-length distribution is significantly right-skewed, 
researchers have advocated using other more representative measures for the assessment of chart performance. These include the standard deviation of the run-length $(S D R L)$ and other percentiles of the run-length, more specifically, the median run-length $(M R L)$, which provides additional and more meaningful information about the in-control and out-of-control performances of control charts, not given by the $A R L$. The idea of looking at percentiles, in SPC, goes back to Barnard [17] and more recently researchers such as Gan [18], Chakraborti [19] and Khoo et al. [20] have advocated the use of percentiles, such as the median, for assessment of chart performance. Tables 3 and 4 give the $A R L, S D R L, 5^{\text {th }}, 25^{\text {th }}, 50^{\text {th }}, 75^{\text {th }}$ and $95^{\text {th }}$ percentiles of the run-length distribution for various distributions for Rule 1, the $\mathrm{RR}_{\text {1-of-l }}$ scheme, and Rule 2, the $\mathrm{RR}_{2-o f-2}$ scheme, respectively. The results for Rule 3, the $\mathrm{IRR}_{2-o f-2}$ scheme, are presented in Table 5. The first row of each cell gives the $A R L$ and the $S D R L$ values, respectively, whereas the second row gives the values of the $5^{t h}, 25^{t h}, 50^{t h}, 75^{t h}$ and $95^{t h}$ percentiles (in this order). The distribution with the best run-length characteristics is indicated using grey shading. When two or more columns are shaded it means that the charts perform similarly. This is done for all tables in this paper. Note that, for large shifts, the run-length characteristics converge toward one for the $\mathrm{RR}_{1-o f-1}$ and $\mathrm{IRR}_{2-o f-2}$ schemes and converge toward two for the $\mathrm{RR}_{2 \text { - }}$ of-2 scheme. The largest shift under consideration is $\delta=2$, since the run-length characteristics converge for large shifts, with shifts of magnitude $\delta=0.00(0.25) 2.00$ being under consideration.

For all three rules the charts perform better under the $t$-distribution (with small degrees of freedom) than the standard normal distribution. As the degrees of freedom increases, the $t$ - and standard normal distributions perform similarly, which is to be expected. For all three rules the charts perform best when the underlying process distribution is uniform. When considering the other distributions under consideration, there is a clear pattern in that the run-rules enhanced charts outperform the standard 1-of-1 chart for small to moderate shifts, which is to be expected. 
Table 3. Characteristics of the run-length distribution for Rule 1, the $\mathrm{RR}_{1-\text { of }-1}$ scheme, for the Shewhart MW chart for $m=500, n=5, L C L_{1}=326$ and $U C L_{1}=2174$

\begin{tabular}{|c|c|c|c|c|c|c|c|}
\hline $\operatorname{Shift}(\delta)$ & $N(0,1)$ & $\log N(0,1)$ & $t(4)$ & $t(8)$ & $\operatorname{GAM}(1,1)$ & $U(0,1)$ & $D E(0,1)$ \\
\hline 0.00 & $\begin{array}{c}498.46(531.34) \\
23,143,335,664,1522\end{array}$ & $\begin{array}{c}488.86(502.61) \\
26,140,329,669,1486\end{array}$ & $\begin{array}{c}504.10(525.99) \\
24,137,342,682,1530\end{array}$ & $\begin{array}{c}498.83(523.81) \\
25,135,330,701,1482\end{array}$ & $\begin{array}{c}500.12(529.36) \\
25,144,329,681,1588\end{array}$ & $\begin{array}{c}495.56(548.49) \\
22,134,328,648,1613\end{array}$ & $\begin{array}{c}501.74(523.19) \\
25,135,330,700,1548\end{array}$ \\
\hline 0.25 & $\begin{array}{c}197.86(216.20) \\
10,52,129,263,628\end{array}$ & $\begin{array}{c}509.04(599.86) \\
23,125,316,656,1646\end{array}$ & $\begin{array}{c}169.29(194.08) \\
7,45,109,225,526\end{array}$ & $\begin{array}{c}185.74(201.38) \\
8,48,120,257,568\end{array}$ & $\begin{array}{c}318.84(386.22) \\
14,78,192,408,1065\end{array}$ & $\begin{array}{c}11.31(10.83) \\
1,4,8,15,34\end{array}$ & $\begin{array}{c}287.70(324.38) \\
14,785,185,388,912\end{array}$ \\
\hline 0.50 & $\begin{array}{c}53.05(60.37) \\
3,14,34,69,169 \\
\end{array}$ & $\begin{array}{c}230.53(284.58) \\
10,57,139,299,726 \\
\end{array}$ & $\begin{array}{c}35.31(38.99) \\
2,9,23,47,114 \\
\end{array}$ & $\begin{array}{c}47.26(52.16) \\
3,13,31,63,147 \\
\end{array}$ & $\begin{array}{c}91.93(105.87) \\
4,23,57,122,287 \\
\end{array}$ & $\begin{array}{l}1.82(1.22) \\
1,1,1,2,4\end{array}$ & $\begin{array}{c}94.74(107.51) \\
5,24,60,128,30,309\end{array}$ \\
\hline 0.75 & $\begin{array}{c}16.22(16.25) \\
1,5,11,22,48\end{array}$ & $\begin{array}{c}103.20(127.33) \\
5,25,61,132,341\end{array}$ & $\begin{array}{l}9.50(9.44) \\
1,3,7,13,28\end{array}$ & $\begin{array}{c}13.72(13.98) \\
1,4,9,19,42\end{array}$ & $\begin{array}{l}26.68(30.32) \\
2,7,17,35,83\end{array}$ & $\begin{array}{l}1.00(0.07) \\
1,1,1,1,1\end{array}$ & $\begin{array}{l}31.56(35.14) \\
2,8,21,42,99\end{array}$ \\
\hline 1.00 & $\begin{array}{c}6.52(6.17) \\
1,2,5,9,19\end{array}$ & $\begin{array}{c}42.33(51.06) \\
2,10,26,55,140\end{array}$ & $\begin{array}{c}3.72(3.29) \\
1,1,3,5,10\end{array}$ & $\begin{array}{c}5.50(5.15) \\
1,2,4,7,16\end{array}$ & $\begin{array}{l}7.87(8.51) \\
1,2,5,10,24\end{array}$ & $\begin{array}{l}1.00(0.00) \\
1,1,1,1,1\end{array}$ & $\begin{array}{c}11.88(12.40) \\
1,4,8,16,36\end{array}$ \\
\hline 1.50 & $\begin{array}{l}2.05(1.44) \\
1,1,2,3,5\end{array}$ & $\begin{array}{l}8.41(9.95) \\
1,2,5,11,27\end{array}$ & $\begin{array}{l}1.47(0.84) \\
1,1,1,2,3\end{array}$ & $\begin{array}{l}1.77(1.22) \\
1,1,1,2,4\end{array}$ & $\begin{array}{l}1.39(0.84) \\
1,1,1,2,3\end{array}$ & $\begin{array}{l}1.00(0.00) \\
1,1,1,1,1\end{array}$ & $\begin{array}{l}3.19(2.81) \\
1,1,2,4,9\end{array}$ \\
\hline 1.75 & $\begin{array}{l}1.48(0.85) \\
1,1,1,2,3 \\
\end{array}$ & $\begin{array}{c}4.15(4.63) \\
1,1,3,5,13 \\
\end{array}$ & $\begin{array}{l}1.25(0.55) \\
1,1,1,1,2 \\
\end{array}$ & $\begin{array}{l}1.37(0.72) \\
1,1,1,2,3 \\
\end{array}$ & $\begin{array}{l}1.05(0.24) \\
1,1,1,1,1 \\
\end{array}$ & $\begin{array}{l}1.00(0.00) \\
1,1,1,1,1 \\
\end{array}$ & $\begin{array}{l}2.20(1.64) \\
1,1,2,3,5 \\
\end{array}$ \\
\hline 2.00 & $\begin{array}{l}1.19(0.47) \\
1,1,1,1,2\end{array}$ & $\begin{array}{l}2.26(2.46) \\
1,1,1,3,6\end{array}$ & $\begin{array}{l}1.13(0.39) \\
1,1,1,1,2\end{array}$ & $\begin{array}{l}1.19(0.48) \\
1,1,1,1,2\end{array}$ & $\begin{array}{l}1.00(0.07) \\
1,1,1,1,1\end{array}$ & $\begin{array}{l}1.00(0.00) \\
1,1,1,1,1\end{array}$ & $\begin{array}{l}1.71(1.12) \\
1,1,1,2,4\end{array}$ \\
\hline
\end{tabular}

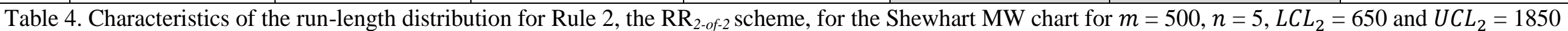

\begin{tabular}{|c|c|c|c|c|c|c|c|}
\hline $\operatorname{Shift}(\delta)$ & $N(0,1)$ & $\log N(0,1)$ & $t(4)$ & $t(8)$ & $\operatorname{GAM}(1,1)$ & $U(0,1)$ & $D E(0,1)$ \\
\hline 0.00 & $\begin{array}{c}493.10(498.47) \\
25,140,323,660,1480\end{array}$ & $\begin{array}{c}492.17(511.38) \\
27,145,334,666,1489\end{array}$ & $\begin{array}{c}493.27(496.33) \\
22,137,345,653,1460\end{array}$ & $\begin{array}{c}497.28(504.79) \\
24,143,342,681,1496\end{array}$ & $\begin{array}{c}498.27(522.02) \\
24,132,332,679,1548\end{array}$ & $\begin{array}{c}499.27(518.89) \\
29,141,338,687,1544\end{array}$ & $\begin{array}{c}494.72(507.70) \\
24,127,338,687,1544\end{array}$ \\
\hline 0.25 & $\begin{array}{c}130.34(147.01) \\
7,35,84,177,404\end{array}$ & $\begin{array}{c}214.69(262.18) \\
11,55,125,276,710\end{array}$ & $\begin{array}{c}93.72(100.97) \\
6,25,62,123,302\end{array}$ & $\begin{array}{l}121.85(139.34) \\
6,32,78,161,383\end{array}$ & $\begin{array}{c}111.36(136.88) \\
7,29,70,144,350\end{array}$ & $\begin{array}{c}7.73(6.52) \\
2,3,6,10,20\end{array}$ & $\begin{array}{c}169.67(190.59) \\
8,44,108,228,558\end{array}$ \\
\hline 0.50 & $\begin{array}{r}28.06(28.83) \\
3,8,19,38,84\end{array}$ & $\begin{array}{c}44.27(52.55) \\
3,12,28,56,140\end{array}$ & $\begin{array}{l}15.73(14.60) \\
2,5,11,22,47\end{array}$ & $\begin{array}{l}23.45(23.87) \\
2,7,16,31,71\end{array}$ & $\begin{array}{c}16.37(17.35) \\
1,4,8,16,39\end{array}$ & $\begin{array}{l}2.14(0.49) \\
2,2,2,2,3\end{array}$ & $\begin{array}{c}39.80(42.41) \\
3,12,26,53,123\end{array}$ \\
\hline 0.75 & $\begin{array}{l}9.03(7.83) \\
2,4,7,12,25\end{array}$ & $\begin{array}{l}11.21(11.76) \\
2,4,7,14,33\end{array}$ & $\begin{array}{c}5.61(4.35) \\
2,2,4,7,14\end{array}$ & $\begin{array}{c}7.61(6.69) \\
2,3,6,10,21\end{array}$ & $\begin{array}{c}3.97(2.85) \\
2,2,3,5,10\end{array}$ & $\begin{array}{l}2.00(0.00) \\
2,2,2,2,2\end{array}$ & $\begin{array}{l}12.95(12.83) \\
2,4,9,17,38\end{array}$ \\
\hline 1.00 & $\begin{array}{c}4.41(3.19) \\
2,2,3,6,11\end{array}$ & $\begin{array}{c}4.04(3.16) \\
2,2,3,5,10\end{array}$ & $\begin{array}{l}3.27(1.90) \\
2,2,2,4,7\end{array}$ & $\begin{array}{l}3.90(2.62) \\
2,2,3,5,9\end{array}$ & $\begin{array}{l}2.23(0.70) \\
2,2,2,2,4\end{array}$ & $\begin{array}{l}2.00(0.00) \\
2,2,2,2,2\end{array}$ & $\begin{array}{c}6.46(5.41) \\
2,3,5,8,17\end{array}$ \\
\hline 1.50 & $\begin{array}{l}2.33(0.80) \\
2,2,2,2,4\end{array}$ & $\begin{array}{l}2.04(0.31) \\
2,2,2,2,2\end{array}$ & $\begin{array}{l}2.20(0.60) \\
2,2,2,2,4\end{array}$ & $\begin{array}{l}2.28(0.78) \\
2,2,2,2,4\end{array}$ & $\begin{array}{l}2.00(0.00) \\
2,2,2,2,2\end{array}$ & $\begin{array}{l}2.00(0.00) \\
2,2,2,2,2\end{array}$ & $\begin{array}{l}3.16(1.81) \\
2,2,2,4,7\end{array}$ \\
\hline 1.75 & $\begin{array}{l}2.11(0.44) \\
2,2,2,2,3\end{array}$ & $\begin{array}{l}2.00(0.09) \\
2,2,2,2,2\end{array}$ & $\begin{array}{l}2.08(0.37) \\
2,2,2,2,3\end{array}$ & $\begin{array}{l}2.11(0.44) \\
2,2,2,2,3\end{array}$ & $\begin{array}{l}2.00(0.00) \\
2,2,2,2,2\end{array}$ & $\begin{array}{l}2.00(0.00) \\
2,2,2,2,2\end{array}$ & $\begin{array}{l}2.55(1.08) \\
2,2,2,3,5\end{array}$ \\
\hline 2.00 & $\begin{array}{l}2.03(0.23) \\
2,2,2,2,2\end{array}$ & $\begin{array}{l}2.00(0.00) \\
2,2,2,2,2\end{array}$ & $\begin{array}{l}2.02(0.19) \\
2,2,2,2,2\end{array}$ & $\begin{array}{l}2.04(0.25) \\
2,2,2,2,2\end{array}$ & $\begin{array}{l}2.00(0.00) \\
2,2,2,2,2\end{array}$ & $\begin{array}{l}2.00(0.00) \\
2,2,2,2,2\end{array}$ & $\begin{array}{l}2.31(0.77) \\
2,2,2,2,4\end{array}$ \\
\hline
\end{tabular}


Table 5. Characteristics of the run-length distribution for Rule 3, the $\mathrm{IRR}_{2-o f-2}$ scheme, for the Shewhart $\mathrm{MW}$ chart for $m=500, n=5, L C L_{3}=$ 650, $L W L_{3}=326, U W L_{3}=1850$ and $U C L_{3}=2174$

\begin{tabular}{|c|c|c|c|c|c|c|c|}
\hline $\operatorname{Shift}(\delta)$ & $N(0,1)$ & $\log N(0,1)$ & $t(4)$ & $t(8)$ & $\operatorname{GAM}(1,1)$ & $U(0,1)$ & $D E(0,1)$ \\
\hline 0.00 & $\begin{array}{c}500.21(544.02) \\
28,123,309,634,1508 \\
\end{array}$ & $\begin{array}{c}507.58(534.33) \\
22,139,339,691,1515\end{array}$ & $\begin{array}{c}488.58(502.52) \\
24,131,318,638,1487\end{array}$ & $\begin{array}{c}492.46(505.52) \\
23,122,328,683,1532\end{array}$ & $\begin{array}{c}496.97(500.39) \\
22,143,334,6921520\end{array}$ & $\begin{array}{c}498.37(500.81) \\
20,131,322,637,1567\end{array}$ & $\begin{array}{c}484.70(498.25) \\
25,129,338,644,1409\end{array}$ \\
\hline 0.25 & $\begin{array}{l}130.13(142.18) \\
6,32,78,148,336 \\
\end{array}$ & $\begin{array}{c}272.34(288.37) \\
23,143,326,654,1520\end{array}$ & $\begin{array}{c}119.75(145.65) \\
5,31,78,167,403 \\
\end{array}$ & $\begin{array}{l}130.51(131.97) \\
5,37,94,174,394 \\
\end{array}$ & $\begin{array}{c}209.66(223.03) \\
11,54,135,267,584\end{array}$ & $\begin{array}{c}11.86(12.27) \\
1,3,8,14,32 \\
\end{array}$ & $\begin{array}{c}187.79(230.60) \\
14,785,185,388,912 \\
\end{array}$ \\
\hline 0.50 & $\begin{array}{c}33.51(38.48) \\
3,13,21,42,112\end{array}$ & $\begin{array}{c}112.27(124.36) \\
7,39,102,223,528\end{array}$ & $\begin{array}{l}24.84(24.19) \\
2,6,15,30,81\end{array}$ & $\begin{array}{c}32.09(30.90) \\
2,10,23,43,96\end{array}$ & $\begin{array}{c}57.79(67.24) \\
4,16,24,65,158\end{array}$ & $\begin{array}{l}1.82(1.22) \\
1,1,1,2,4\end{array}$ & $\begin{array}{c}63.14(70.23) \\
3,17,26,66,155\end{array}$ \\
\hline 0.75 & $\begin{array}{l}10.63(10.93) \\
1,3,8,11,30 \\
\end{array}$ & $\begin{array}{c}65.05(80.44) \\
4,18,26,70,159 \\
\end{array}$ & $\begin{array}{c}6.25(6.31) \\
1,2,5,8,18 \\
\end{array}$ & $\begin{array}{c}11.01(11.23) \\
1,3,8,15,30 \\
\end{array}$ & $\begin{array}{l}16.33(18.52) \\
1,4,12,21,49 \\
\end{array}$ & $\begin{array}{l}1.00(0.07) \\
1,1,1,1,1 \\
\end{array}$ & $\begin{array}{l}25.13(28.49) \\
2,7,16,32,82 \\
\end{array}$ \\
\hline 1.00 & $\begin{array}{c}4.33(4.19) \\
1,2,3,5,10\end{array}$ & $\begin{array}{l}28.89(35.09) \\
3,7,17,33,84 \\
\end{array}$ & $\begin{array}{l}2.33(2.04) \\
1,1,2,4,6\end{array}$ & $\begin{array}{c}4.29(3.57) \\
1,2,3,6,12\end{array}$ & $\begin{array}{l}5.19(5.65) \\
1,2,4,6,15\end{array}$ & $\begin{array}{l}1.00(0.00) \\
1,1,1,1,1\end{array}$ & $\begin{array}{c}7.98(8.69) \\
1,2,5,11,23\end{array}$ \\
\hline 1.50 & $\begin{array}{l}1.39(0.99) \\
1,1,2,2,3 \\
\end{array}$ & $\begin{array}{l}11.23(12.35) \\
1,3,5,15,36 \\
\end{array}$ & $\begin{array}{l}1.33(1.00) \\
1,1,1,1,2\end{array}$ & $\begin{array}{l}1.66(1.09) \\
1,1,1,2,4 \\
\end{array}$ & $\begin{array}{l}1.36(0.90) \\
1,1,1,2,3 \\
\end{array}$ & $\begin{array}{l}1.00(0.00) \\
1,1,1,1,1 \\
\end{array}$ & $\begin{array}{l}2.23(1.81) \\
1,1,2,3,9 \\
\end{array}$ \\
\hline 1.75 & $\begin{array}{l}1.33(0.78) \\
1,1,1,1,2 \\
\end{array}$ & $\begin{array}{c}5.49(5.31) \\
1,2,4,7,16 \\
\end{array}$ & $\begin{array}{l}1.25(0.51) \\
1,1,1,1,2 \\
\end{array}$ & $\begin{array}{l}1.32(0.66) \\
1,1,1,1,3\end{array}$ & $\begin{array}{l}1.04(0.21) \\
1,1,1,1,1\end{array}$ & $\begin{array}{l}1.00(0.00) \\
1,1,1,1,1 \\
\end{array}$ & $\begin{array}{l}1.72(1.22) \\
1,1,1,2,4\end{array}$ \\
\hline 2.00 & $\begin{array}{l}1.14(0.51) \\
1,1,1,1,2 \\
\end{array}$ & $\begin{array}{l}3.11(2.50) \\
1,1,2,4,8 \\
\end{array}$ & $\begin{array}{l}1.13(0.38) \\
1,1,1,1,2 \\
\end{array}$ & $\begin{array}{l}1.13(0.39) \\
1,1,1,1,2 \\
\end{array}$ & $\begin{array}{l}1.00(0.00) \\
1,1,1,1,1 \\
\end{array}$ & $\begin{array}{l}1.00(0.00) \\
1,1,1,1,1 \\
\end{array}$ & $\begin{array}{l}1.45(0.87) \\
1,1,1,2,3 \\
\end{array}$ \\
\hline
\end{tabular}

Table 6. $A R L$ values of the $\mathrm{RR}_{1-o f-1}, \mathrm{RR}_{2-o f-2}$ and $\mathrm{IRR}_{2-o f-2}$ Shewhart $\mathrm{MW}$ charts under the $N(0,1), t(4)$ and $G A M(1,1)$ distributions for $m=500$ and $n=5$

\begin{tabular}{|c|c|c|c|c|c|c|c|c|c|}
\hline \multirow{2}{*}{ Shifts } & \multicolumn{3}{|c|}{$N(0,1)$} & \multicolumn{3}{|c|}{$t(4)$} & \multicolumn{3}{|c|}{$\operatorname{GAM}(1,1)$} \\
\hline & $\mathrm{RR}_{\text {l-of-1 }}$ & $\mathrm{RR}_{2-o f-2}$ & $\mathrm{IRR}_{2-o f-2}$ & $\mathrm{RR}_{\text {I-of-1 }}$ & $\mathrm{RR}_{2-o f-2}$ & $\mathrm{IRR}_{2-o f-2}$ & $\mathrm{RR}_{1-o f-1}$ & $\mathrm{RR}_{2-o f-2}$ & $\mathrm{IRR}_{2-o f-2}$ \\
\hline & $498.46(531.34)$ & $493.10(498.47)$ & $500.21(544.02)$ & $504.10(525.99)$ & 493.27(496.33) & $488.58(502.52)$ & 500.12(529.36) & $498.27(522.02)$ & $496.97(500.39)$ \\
\hline 0.00 & $23,143,335,664,1522$ & $25,140,323,660,1480$ & $28,123,309,634,1508$ & $24,137,342,682,1530$ & $22,137,345,653,1460$ & $24,131,318,638,1487$ & $25,144,329,681,1588$ & $24,132,332,679,1548$ & $22,143,334,6921520$ \\
\hline 0.25 & $\begin{array}{c}197.86(216.20) \\
10,52,129,263,628 \\
\end{array}$ & $\begin{array}{l}130.34(147.01) \\
7,35,84,177,404\end{array}$ & $\begin{array}{c}130.13(142.18) \\
6,32,78,148,336 \\
\end{array}$ & $\begin{array}{c}169.29(194.08) \\
7,45,109,225,526 \\
\end{array}$ & $\begin{array}{c}93.72(100.97) \\
6,25,62,123,302 \\
\end{array}$ & $\begin{array}{c}119.75(145.65) \\
5,31,78,167,403 \\
\end{array}$ & $\begin{array}{c}318.84(386.22) \\
14,78,192,408,1065 \\
\end{array}$ & $\begin{array}{c}111.36(136.88) \\
7,29,70,144,350 \\
\end{array}$ & $\begin{array}{c}209.66(223.03) \\
11,54,135,267,584 \\
\end{array}$ \\
\hline 0.50 & $\begin{array}{c}53.05(60.37) \\
3,14,34,69,169 \\
\end{array}$ & $\begin{array}{l}28.06(28.83) \\
3,8,19,38,84 \\
\end{array}$ & $\begin{array}{c}33.51(38.48) \\
3,13,21,42,112 \\
\end{array}$ & $\begin{array}{c}35.31(38.99) \\
2,9,23,47,114 \\
\end{array}$ & $\begin{array}{l}15.73(14.60) \\
2,5,11,22,47 \\
\end{array}$ & $\begin{array}{l}24.84(24.19) \\
2,6,15,30,81 \\
\end{array}$ & $\begin{array}{c}91.93(105.87) \\
4,23,57,122,287 \\
\end{array}$ & $\begin{array}{c}16.37(17.35) \\
1,4,8,16,39 \\
\end{array}$ & $\begin{array}{c}57.79(67.24) \\
4,16,24,65,158 \\
\end{array}$ \\
\hline 0.75 & $\begin{array}{c}16.22(16.25) \\
1,5,11,22,48\end{array}$ & $\begin{array}{l}9.03(7.83) \\
2,4,7,12,25\end{array}$ & $\begin{array}{l}10.63(10.93) \\
1,3,8,11,30 \\
\end{array}$ & $\begin{array}{c}9.50(9.44) \\
1,3,7,13,28\end{array}$ & $\begin{array}{c}5.61(4.35) \\
2,2,4,7,14\end{array}$ & $\begin{array}{c}6.25(6.31) \\
1,2,5,8,18\end{array}$ & $\begin{array}{l}26.68(30.32) \\
2,7,17,35,83 \\
\end{array}$ & $\begin{array}{c}3.97(2.85) \\
2,2,3,5,10\end{array}$ & $\begin{array}{l}16.33(18.52) \\
1,4,12,21,49\end{array}$ \\
\hline 1.00 & $\begin{array}{c}6.52(6.17) \\
1,2,5,9,19 \\
\end{array}$ & $\begin{array}{c}4.41(3.19) \\
2,2,3,6,11\end{array}$ & $\begin{array}{c}4.33(4.19) \\
1,2,3,5,10 \\
\end{array}$ & $\begin{array}{c}3.72(3.29) \\
1,1,3,5,10\end{array}$ & $\begin{array}{l}3.27(1.90) \\
2,2,2,4,7 \\
\end{array}$ & $\begin{array}{l}2.33(2.04) \\
1,1,2,4,6\end{array}$ & $\begin{array}{l}7.87(8.51) \\
1,2,5,10,24 \\
\end{array}$ & $\begin{array}{l}2.23(0.70) \\
2,2,2,2,4 \\
\end{array}$ & $\begin{array}{l}5.19(5.65) \\
1,2,4,6,15\end{array}$ \\
\hline 1.50 & $\begin{array}{l}2.05(1.44) \\
1,1,2,3,5 \\
\end{array}$ & $\begin{array}{l}2.33(0.80) \\
2,2,2,2,4 \\
\end{array}$ & $\begin{array}{l}1.39(0.99) \\
1,1,2,2,3 \\
\end{array}$ & $\begin{array}{l}1.47(0.84) \\
1,1,1,2,3 \\
\end{array}$ & $\begin{array}{l}2.20(0.60) \\
2,2,2,2,4 \\
\end{array}$ & $\begin{array}{l}1.33(1.00) \\
1,1,1,1,2 \\
\end{array}$ & $\begin{array}{l}1.39(0.84) \\
1,1,1,2,3 \\
\end{array}$ & $\begin{array}{l}2.00(0.00) \\
2,2,2,2,2 \\
\end{array}$ & $\begin{array}{l}1.36(0.90) \\
1,1,1,2,3 \\
\end{array}$ \\
\hline 1.75 & $\begin{array}{l}1.48(0.85) \\
1,1,1,2,3\end{array}$ & $\begin{array}{l}2.11(0.44) \\
2,2,2,2,3\end{array}$ & $\begin{array}{l}1.33(0.78) \\
1,1,1,1,2\end{array}$ & $\begin{array}{l}1.25(0.55) \\
1,1,1,1,2\end{array}$ & $\begin{array}{l}2.08(0.37) \\
2,2,2,2,3\end{array}$ & $\begin{array}{l}1.25(0.51) \\
1,1,1,1,2\end{array}$ & $\begin{array}{l}1.05(0.24) \\
1,1,1,1,1\end{array}$ & $\begin{array}{l}2.00(0.00) \\
2,2,2,2,2\end{array}$ & $\begin{array}{l}1.04(0.21) \\
1,1,1,1,1\end{array}$ \\
\hline 2.00 & $\begin{array}{l}1.19(0.47) \\
1,1,1,1,2\end{array}$ & $\begin{array}{c}2.03(0.23) \\
2,2,2,2,2\end{array}$ & $\begin{array}{l}1.14(0.51) \\
1,1,1,1,2\end{array}$ & $\begin{array}{c}1.13(0.39) \\
1,1,1,1,2\end{array}$ & $\begin{array}{c}2.02(0.19) \\
2,2,2,2,2\end{array}$ & $\begin{array}{c}1.13(0.38) \\
1,1,1,1,2\end{array}$ & $\begin{array}{c}1.00(0.07) \\
1,1,1,1,1\end{array}$ & $\begin{array}{c}2.00(0.00) \\
2,2,2,2,2\end{array}$ & $\begin{array}{l}1.00(0.00) \\
1,1,1,1,1\end{array}$ \\
\hline
\end{tabular}


In Table 6 we compare the $\mathrm{RR}_{1-o f-1}, \mathrm{RR}_{2-o f-2}$ and $\mathrm{IRR}_{2-o f-2}$ Shewhart $\mathrm{MW}$ charts under the $N(0,1), t(4)$ and $\operatorname{GAM}(1,1)$ distributions. For small shifts, no matter the nature of the underlying distribution, the $\mathrm{RR}_{2-o f-2} \mathrm{scheme}$ performs best. For moderate shifts the IRR $\mathrm{IR}_{2-o f-2}$ scheme performs best. For large shifts the $\mathrm{RR}_{1-o f-1}$ and IRR $\mathrm{IR}_{2-o f-2}$ schemes perform similarly and best, since the smallest value that their run-length can take on equals 1 , whereas, for the $\mathrm{RR}_{2-o f-2}$ scheme the smallest value that its run-length can take on equals 2 , since at least two points are needed to give a signal. The results from Table 6 are illustrated in Figure 3 (d) - (f).

To illustrate the efficiency of the $\mathrm{IRR}_{2-o f-2}$ and $\mathrm{RR}_{2-o f-2}$ schemes we illustrate their performances under some of the distributions by presenting some graphs. Figures 1 (a), (b) and (c) show that the Shewhart MW chart is more efficient under non-normal distributions and we can see that the chart performs best under the uniform distribution.

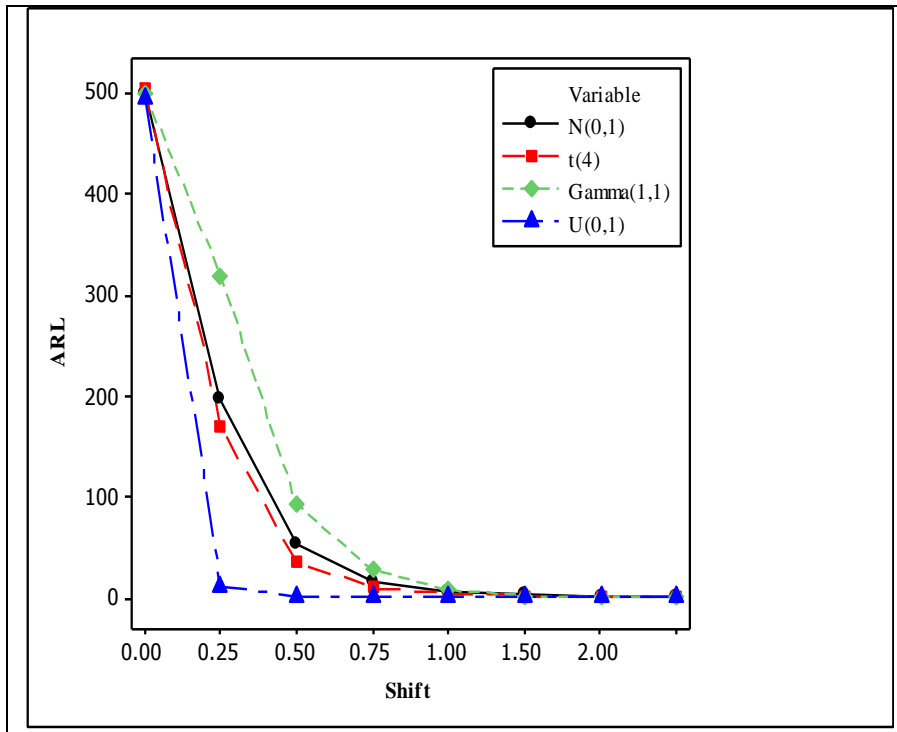

Figure 1 (a). $A R L$ versus shift for the $\mathrm{RR}_{\text {l-of-l }}$ Shewhart MW control chart under the $N(0,1), t(4), G A M(1,1)$ and $U(0,1)$.

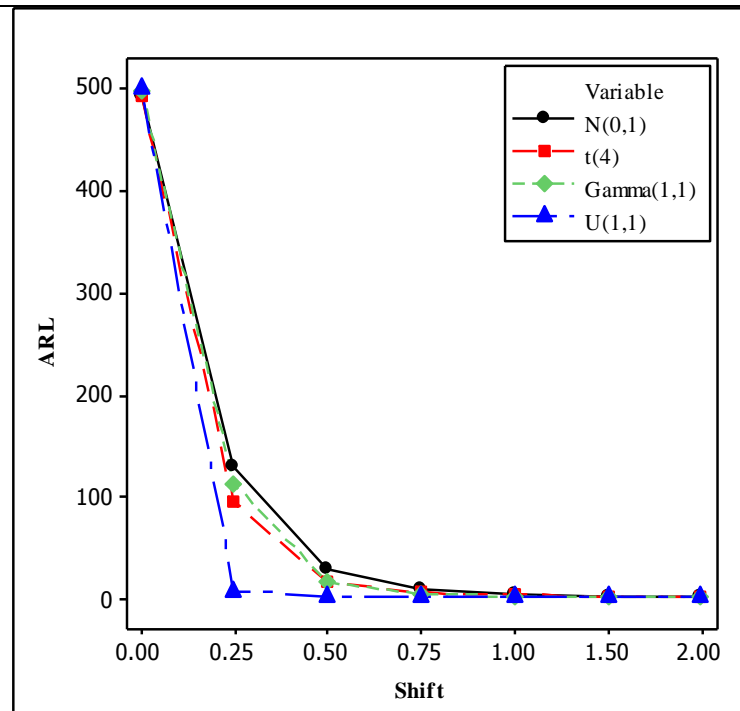

Figure 1(b). $A R L$ versus shift for the $\mathrm{RR}_{2-o f-2}$ Shewhart MW control chart under the $N(0,1), t(4), G A M(1,1)$ and $U(0,1)$.

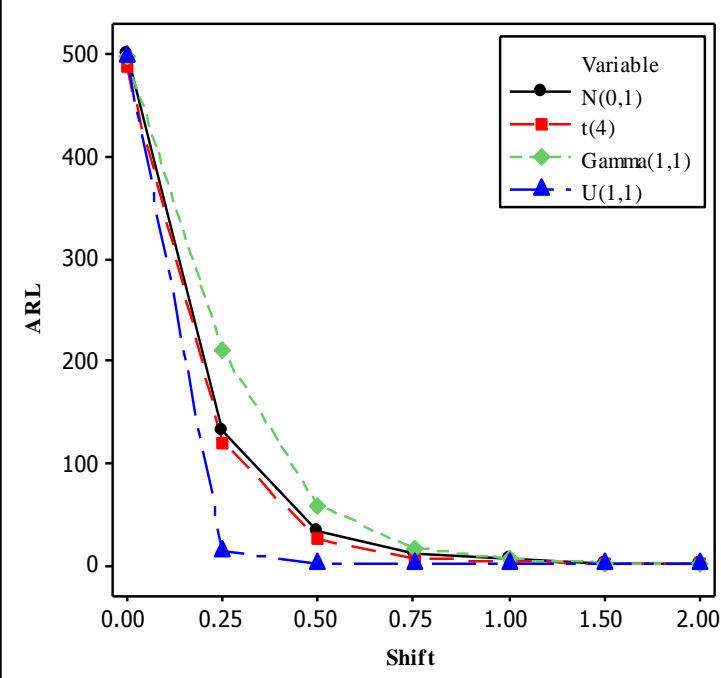

Figure 1 (c). $A R L$ versus shift for the $\mathrm{IRR}_{2-o f-2}$ Shewhart MW control chart under the $N(0,1), t(4), G A M(1,1)$ and $U(0,1)$. 


\section{Comparison of the MWRR control charts with other competing charts}

It is meaningful to compare the runs-rule enhanced MW charts with other available nonparametric Shewhart-type charts. Thus we compare the $\mathrm{RR}_{1-o f-1,} \mathrm{RR}_{2-o f-2}$ and $\mathrm{IRR}_{2-o f-2}$ Shewhart $\mathrm{MW}$ charts to the $\mathrm{RR}_{1-\text { of- } 1}$ and $\mathrm{RR}_{2-o f-2}$ Shewhart precedence charts proposed by Chakraborti et al. [21] and Chakraborti et al. [10], respectively. In the latter papers the $N(0,1), G A M(1,1)$ and $t(4)$ distributions were considered and, accordingly, the same distributions are considered here. For benchmarking, the parametric $\mathrm{RR}_{1-o f-1,} \mathrm{RR}_{2-o f-2}$ and $\mathrm{IRR}_{2-o f-2}$ Shewhart $\bar{X}$ charts are also included in the performance comparison under the normal and non-normal distributions regardless of their non-robustness property (see Chakraborti et al. (2004)). The results are shown in Tables 7, 8 and 9, respectively.

From Table 7 it can be seen that, under the $N(0,1)$ distribution, the parametric Shewhart $\bar{X}$ chart performs best. This is to be expected, since the underlying assumption of normality was met. Under the $t(4)$ and $\operatorname{GAM}(1,1)$ distributions, see Tables 8 and 9, respectively, the $\mathrm{RR}_{2-o f-2}$ Shewhart $\mathrm{MW}$ chart performs best for small to moderate shifts whereas the $\mathrm{IRR}_{1-o f-1}$ Shewhart MW chart performs best for large shifts. The Shewhart precedence charts perform second best, whereas the parametric Shewhart $\bar{X}$ chart performs worst. The results of Tables 7 to 9 are illustrated in Figures 2 (a) - (f) and 3 (a) - (c) where it can be seen that the parametric

Shewhart $\bar{X}$ charts perform best under normality and the Shewhart MW chart performs best when the underlying process distribution is non-normal. 
Table 7. $A R L$ and $S D R L$ values for the $\mathrm{RR}_{1-o f-1}$ and $\mathrm{RR}_{2-o f-2}$ Shewhart $\bar{X}, \mathrm{MW}$ and precedence charts for the $N(0,1)$ distribution when $m=500, j=3$ and $n=5$

\begin{tabular}{|c|c|c|c|c|c|c|c|c|c|c|}
\hline \multirow{3}{*}{ Shift $(\delta)$} & \multicolumn{3}{|c|}{ Rule 1: $\mathrm{RR}_{l-o f-I}$} & \multicolumn{4}{|c|}{ Rule 2: $\mathrm{RR}_{2-o f-2}$} & \multicolumn{3}{|c|}{ Rule 3: $\mathrm{IRR}_{2-o f-2}$} \\
\hline & Shewhart $\bar{X}$ & MW & Precedence & Shewhart $\bar{X}$ & $\mathrm{MW}$ & Prec & dence & Shewhart $\bar{X}$ & MW & Precedence \\
\hline & $A R L \quad S D R L$ & $A R L \quad S D R L$ & $S D R L$ & $A R L \quad S D R L$ & ARL $\quad S D R L$ & ARL & $S D R L$ & $A R L \quad S D R L$ & $A R L \quad S D R L$ & $A R L \quad S D R L$ \\
\hline 0.00 & 500.00511 .14 & 498.46531 .34 & 520.27613 .67 & $\begin{array}{ll}502.37 & 519.24 \\
\end{array}$ & 493.10498 .47 & 490.21 & 554.18 & 523.19599 .63 & 500.21544 .02 & 505.24722 .71 \\
\hline 0.25 & 184.12216 .66 & 197.86216 .20 & $261.60 \quad 329.17$ & $117.00 \quad 122.92$ & $130.34 \quad 147.01$ & 170.07 & 203.00 & 179.98198 .68 & $\begin{array}{ll}130.13 & 142.18\end{array}$ & 142.50149 .69 \\
\hline 0.50 & $\begin{array}{ll}43.38 & 48.51 \\
\end{array}$ & $\begin{array}{ll}53.05 & 60.37 \\
\end{array}$ & $\begin{array}{ll}77.73 & 95.38 \\
\end{array}$ & $23.48 \quad 21.96$ & $28.06 \quad 28.83$ & 39.37 & 43.17 & $\begin{array}{ll}33.04 & 40.61 \\
\end{array}$ & 33.5138 .48 & $33.14 \quad 27.94$ \\
\hline 0.75 & $\begin{array}{ll}13.12 & 13.71 \\
\end{array}$ & $16.22 \quad 16.25$ & $\begin{array}{ll}25.79 & 29.64\end{array}$ & $\begin{array}{ll}7.68 & 6.78 \\
\end{array}$ & 7.83 & 12.99 & 12.60 & $18.17 \quad 19.06$ & $\begin{array}{ll}10.63 & 10.93\end{array}$ & $\begin{array}{ll}18.23 & 19.48\end{array}$ \\
\hline 1.00 & 4.93 & 6.17 & $10.26 \quad 10.93$ & 2.66 & 3.19 & 5.99 & 4.90 & $4.12 \quad 4.83$ & $4.33 \quad 4.19$ & $6.04 \quad 5.03$ \\
\hline 1.50 & 1.08 & 1.44 & 2.34 & 0.62 & 0.80 & 2.67 & 1.26 & $1.36 \quad 1.03$ & $\begin{array}{ll}1.39 & 0.99\end{array}$ & $2.12 \quad 1.59$ \\
\hline 2.00 & 0.32 & 0.47 & 0.75 & 0.16 & 0.23 & 2.10 & 0.41 & $1.09 \quad 0.31$ & $1.14 \quad 0.51$ & $1.48 \quad 0.95$ \\
\hline
\end{tabular}

Table 8. $A R L$ and $S D R L$ values for the $\mathrm{RR}_{1-o f-1}$ and $\mathrm{RR}_{2-o f-2}$ Shewhart $\bar{X}$, MW and precedence charts for the $t(4)$ distribution when $m=500, j=3$ and $n=5$

\begin{tabular}{|c|c|c|c|c|c|c|c|c|c|c|c|c|c|c|}
\hline \multirow{3}{*}{ Shift $(\delta)$} & \multicolumn{5}{|c|}{ Rule 1: $\mathrm{RR}_{I-o f-1}$} & \multicolumn{5}{|c|}{ Rule 2: $\mathrm{RR}_{2-o f-2}$} & \multicolumn{4}{|c|}{ Rule 3: IRR $_{2-o f-2}$} \\
\hline & Shewhart $\bar{X}$ & \multicolumn{2}{|c|}{ MW } & \multicolumn{2}{|c|}{ Precedence } & Shewhart $\bar{X}$ & \multicolumn{2}{|c|}{ MW } & \multicolumn{2}{|c|}{ Precedence } & Shewhart $\bar{X}$ & \multicolumn{2}{|c|}{ MW } & Precedence \\
\hline & $A R L \quad S D R L$ & $A R L$ & $S D R L$ & $A R L$ & $S D R L$ & $A R L \quad S D R L$ & $A R L$ & $S D R L$ & $A R L$ & $S D R L$ & $A R L \quad S D R L$ & $A R L$ & $S D R L$ & $S D R L$ \\
\hline 0.00 & $517.60 \quad 27217.13$ & 504.10 & 525.99 & 520.27 & 613.67 & $\begin{array}{ll}538.55 & 798.03 \\
\end{array}$ & 493.27 & 496.33 & 490.21 & 554.18 & 535.06992 .25 & 488.58 & 502.52 & $497.48 \quad 644.07$ \\
\hline 0.25 & $361.12 \quad 81.30 .44$ & 169.29 & 194.08 & 328.18 & 426.13 & $\begin{array}{ll}181.58 \quad 508.52 \\
\end{array}$ & 93.72 & 100.97 & 138.19 & 170.25 & $348.48 \quad 883.42$ & 119.75 & 145.65 & 153.56195 .67 \\
\hline 0.50 & 397.4360026 .60 & 35.31 & 38.99 & 117.63 & 167.75 & 445.18886 .59 & 15.73 & 14.60 & 25.09 & 27.66 & $220.68 \quad 800.24$ & 24.84 & 24.19 & $\begin{array}{ll}46.88 & 54.93 \\
\end{array}$ \\
\hline 0.75 & 161.5420545 .26 & 9.50 & 9.44 & 37.43 & 53.44 & $115.42 \quad 297.59$ & 5.61 & 4.35 & 7.43 & 6.66 & $74.25 \quad 341.64$ & 6.25 & 6.31 & $\begin{array}{ll}15.93 & 18.28\end{array}$ \\
\hline 1.00 & 93.9114137 .58 & 3.72 & 3.29 & 12.58 & 16.84 & $41.83 \quad 12.74$ & 3.27 & 1.90 & 3.61 & 2.36 & 36.54300 .28 & 2.33 & 2.04 & $\begin{array}{ll}6.32 & 6.61 \\
\end{array}$ \\
\hline 1.50 & 41.936250 .00 & 1.47 & 0.84 & 2.40 & 2.20 & 18.57896 .44 & 2.20 & 0.60 & 2.17 & 0.55 & $8.79 \quad 108.94$ & 1.33 & 1.00 & $\begin{array}{ll}1.84 & 1.42 \\
\end{array}$ \\
\hline 2.00 & 36.15672 .63 & 1.13 & 0.39 & 1.18 & 0.49 & $2.06 \quad 1.93$ & 2.02 & 0.19 & 2.02 & 0.16 & $4.23 \quad 86.61$ & 1.13 & 0.38 & $\begin{array}{ll}1.11 & 0.39 \\
\end{array}$ \\
\hline
\end{tabular}

Table 9. $A R L$ and $S D R L$ values for the $\mathrm{RR}_{1-o f-1}$ and $\mathrm{RR}_{2-o f-2}$ Shewhart $\bar{X}$, MW and precedence charts for the $G A M(1,1)$ distribution when $m=500, j=3$ and $n=5$

\begin{tabular}{|c|c|c|c|c|c|c|c|c|c|}
\hline \multirow{3}{*}{ Shift $(\delta)$} & \multicolumn{3}{|c|}{ Rule 1: $\mathrm{RR}_{1-\text { of }-1}$} & \multicolumn{3}{|c|}{ Rule 2: $\mathrm{RR}_{2-o f-2}$} & \multicolumn{3}{|c|}{ Rule 3: IRR $_{2 \text { of-2 }}$} \\
\hline & Shewhart $\bar{X}$ & MW & Precedence & Shewhart $\bar{X}$ & MW & Precedence & Shewhart $\bar{X}$ & MW & Precedence \\
\hline & ARL $\quad S D R L$ & ARL $\quad S D R L$ & $S D R L$ & ARL $\quad S D R L$ & ARL $\quad S D R L$ & ARL $\quad S D R L$ & $A R L \quad S D R L$ & ARL $\quad S D R L$ & $S D R L$ \\
\hline 0.00 & 509.21608 .57 & $500.12 \quad 529.36$ & $\begin{array}{ll}520.27 & 613.67 \\
\end{array}$ & 456.89577 .77 & $\begin{array}{ll}498.27 & 522.02\end{array}$ & $490.21 \quad 554.18$ & $480.75 \quad 555.25$ & 496.97500 .39 & $502.33 \quad 718.10$ \\
\hline 0.25 & $204.85 \quad 241.37$ & $318.84 \quad 386.22$ & $600.16 \quad 844.59$ & $123.27 \quad 141.52$ & $111.36 \quad 136.88$ & 310.12405 .49 & $225.70 \quad 242.90$ & 209.66223 .03 & $236.98 \quad 313.90$ \\
\hline 0.50 & $85.99 \quad 100.81$ & $91.93 \quad 105.87$ & $290.46 \quad 406.50$ & $29.55 \quad 30.47$ & $16.37 \quad 17.35$ & 88.52111 .41 & $91.28 \quad 109.67$ & $\begin{array}{ll}57.79 & 67.24 \\
\end{array}$ & $121.54 \quad 154.47$ \\
\hline 0.75 & $37.03 \quad 42.78$ & $26.68 \quad 30.32$ & $141.80 \quad 196.68$ & 9.949 .24 & 2.85 & $28.03 \quad 33.05$ & $55.07 \quad 69.65$ & $16.33 \quad 18.52$ & $58.53 \quad 70.34$ \\
\hline 1.00 & $\begin{array}{ll}16.79 & 18.82 \\
\end{array}$ & 8.51 & $\begin{array}{ll}69.72 & 95.80 \\
\end{array}$ & $\begin{array}{ll}4.55 & 3.51 \\
\end{array}$ & 0.70 & $10.26 \quad 10.74$ & $39.04 \quad 47.37$ & $\begin{array}{ll}5.19 & 5.65 \\
\end{array}$ & $30.20 \quad 36.38$ \\
\hline 1.50 & 4.11 & 0.84 & $\begin{array}{ll}17.67 & 23.33 \\
\end{array}$ & $\begin{array}{ll}2.09 & 0.39\end{array}$ & 0.00 & 1.34 & $\begin{array}{ll}6.96 & 6.93 \\
\end{array}$ & 0.90 & 8.76 \\
\hline 2.00 & 1.53 & 0.07 & 4.96 & $\begin{array}{ll}2.00 & 0.00 \\
\end{array}$ & 0.00 & 0.03 & 2.53 & 0.00 & 2.65 \\
\hline
\end{tabular}



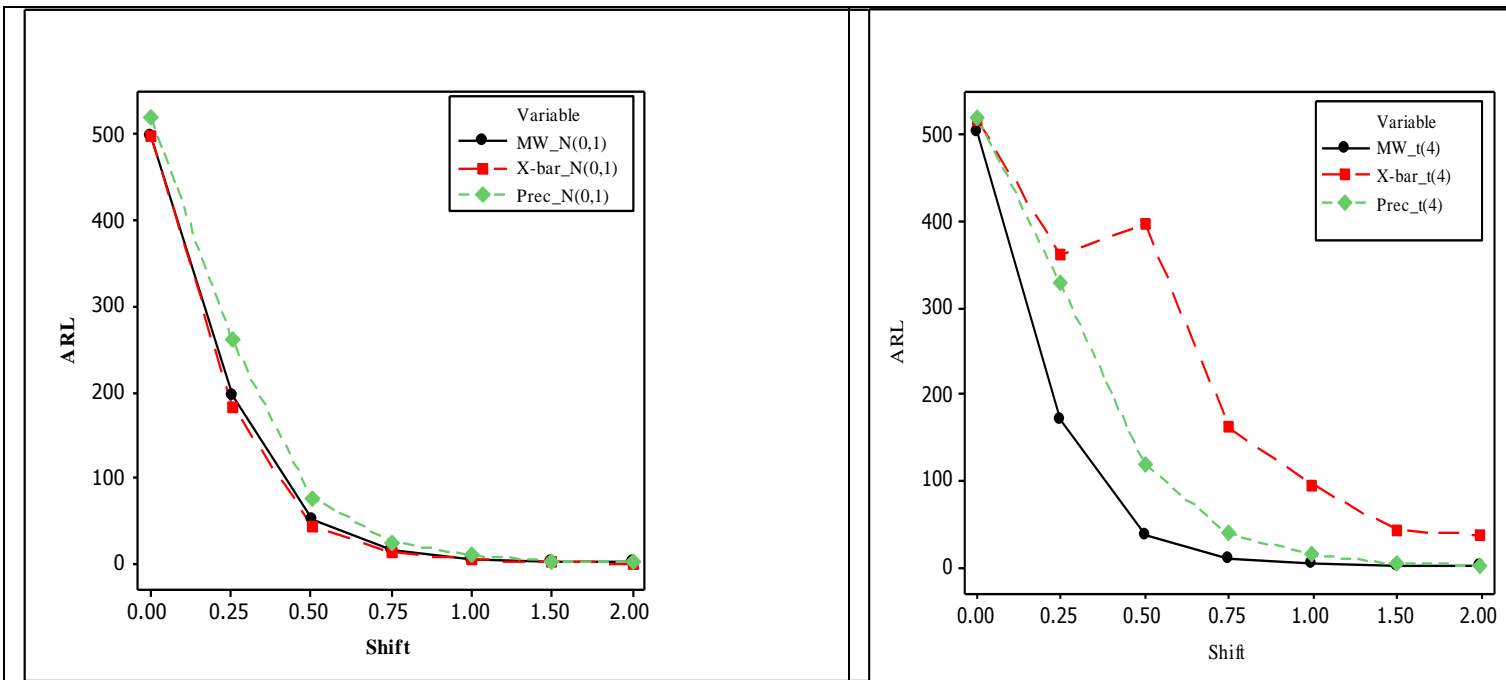

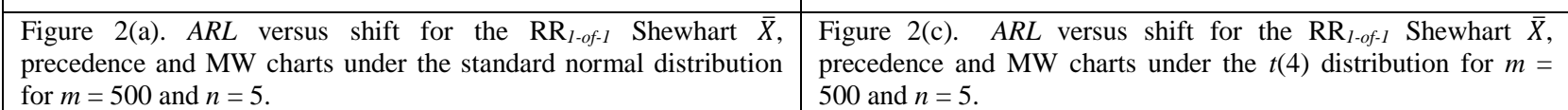
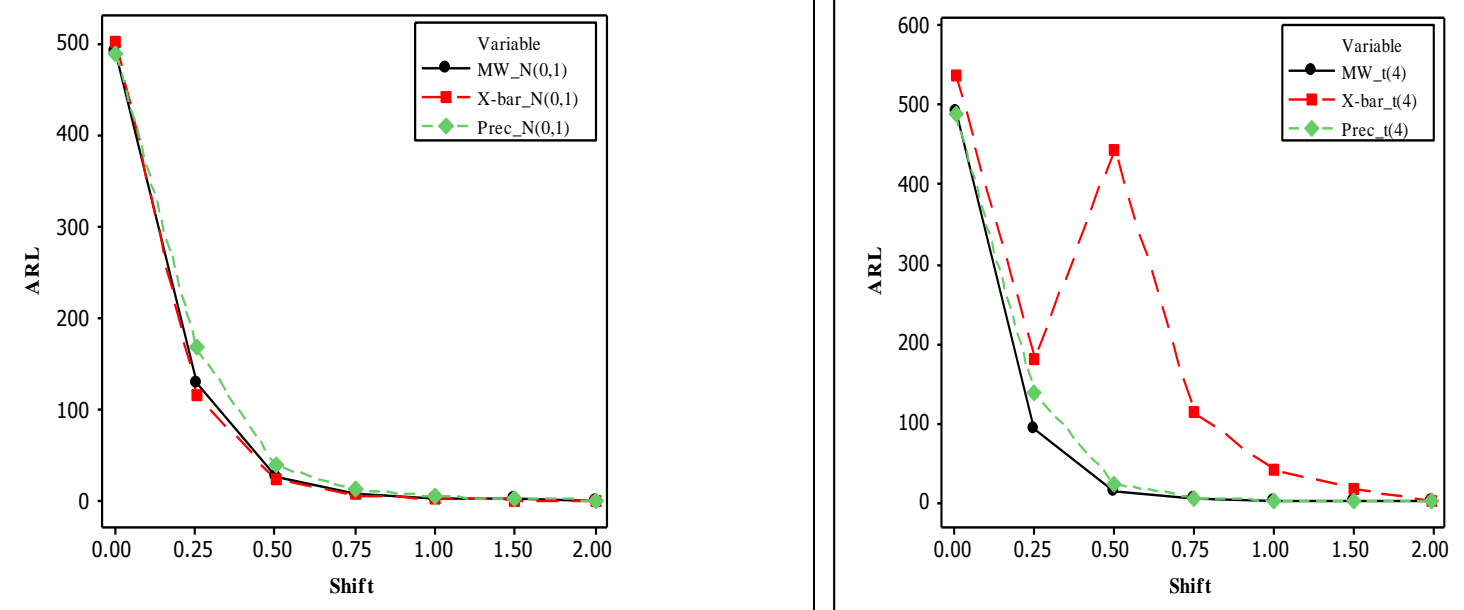

Figure 2(b). $A R L$ versus shift for the $\mathrm{RR}_{2-0 f-2}$ Shewhart $\bar{X}$, precedence and MW charts under the standard normal distribution Figure 2(d). $A R L$ versus shift for the $\mathrm{RR}_{2-o f-2}$ Shewhart $\bar{X}$, precedence and MW charts under the $t(4)$ distribution for $m=$

Figure 2(f). $A R L$ versus shift for the $\mathrm{RR}_{2-o f-2}$ Shewhart $\bar{X}$, precedence for $m=500$ and $n=5$. 500 and $n=5$.

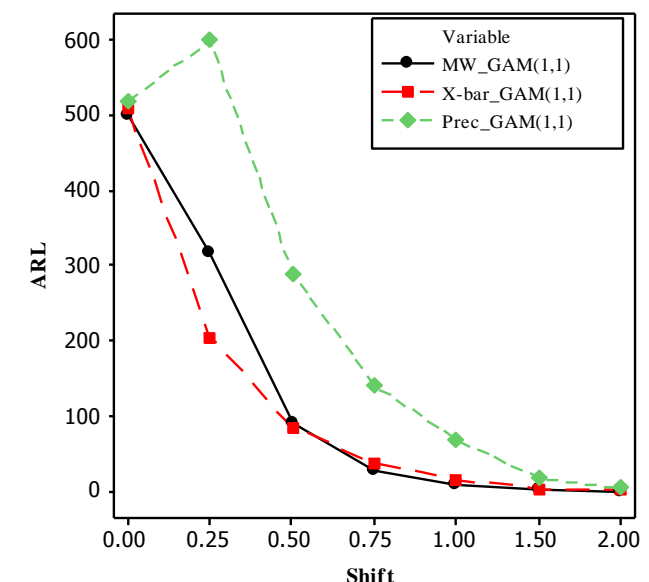

Figure 2(e). $A R L$ versus shift for the $\mathrm{RR}_{1-o f-l}$ Shewhart $\bar{X}$, precedence and MW charts under the $\operatorname{GAM}(1,1)$ distribution for $m=500$ and $n=$

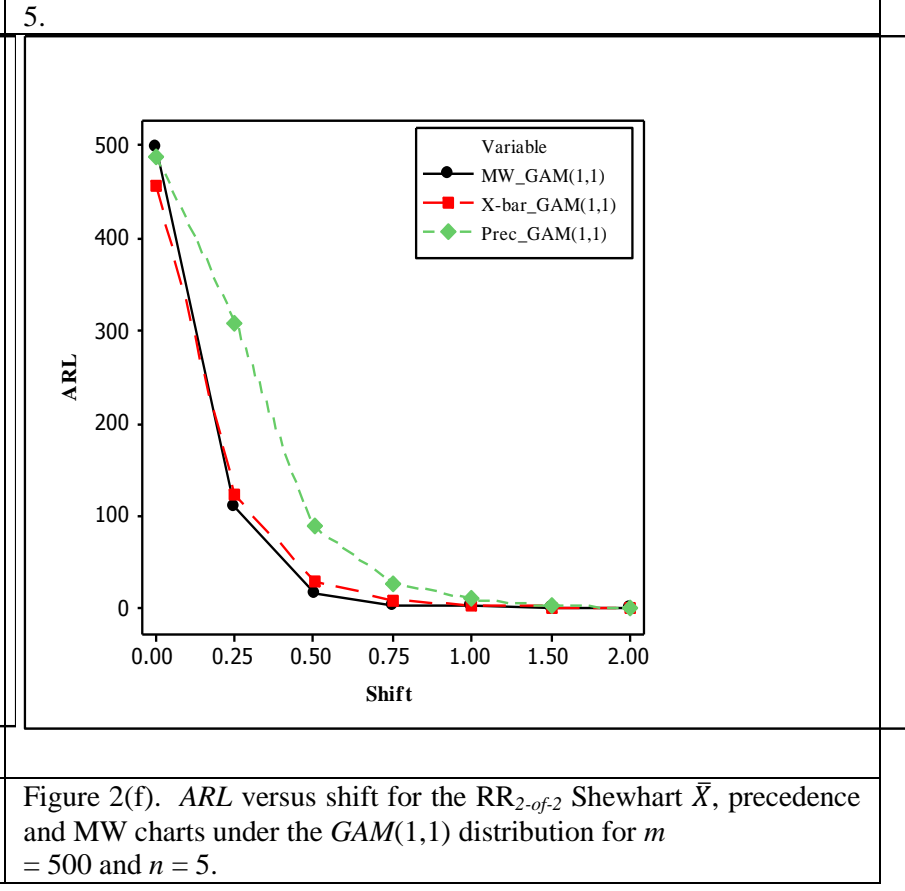




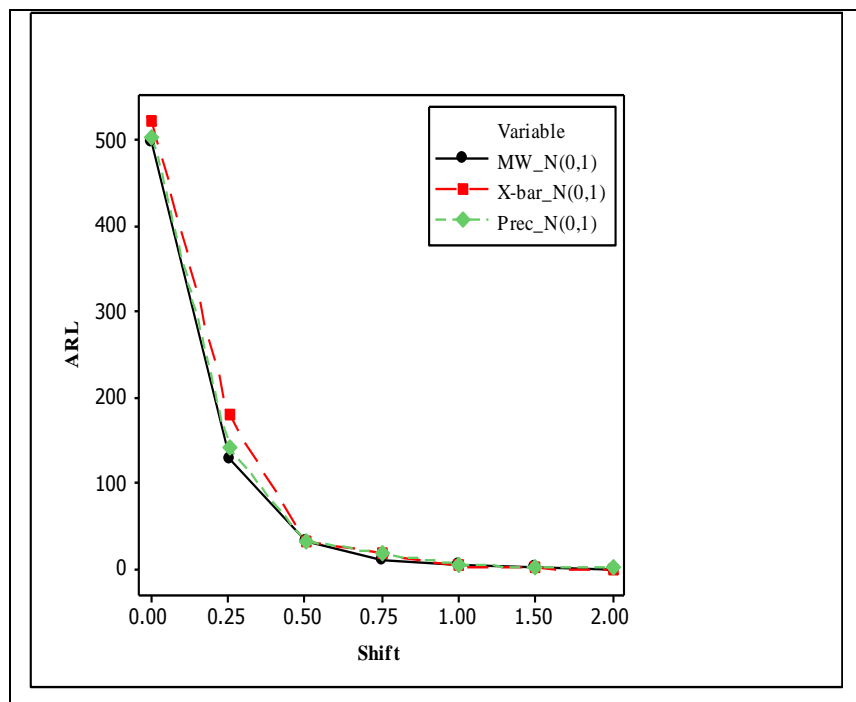

Figure 3(a). ARL versus shift for the $\operatorname{IRR}_{2-o f-2}$ Shewhart $\bar{X}$, precedence and MW charts under the $\operatorname{GAM}(1,1)$ distribution for $m=500$ and $n=5$.

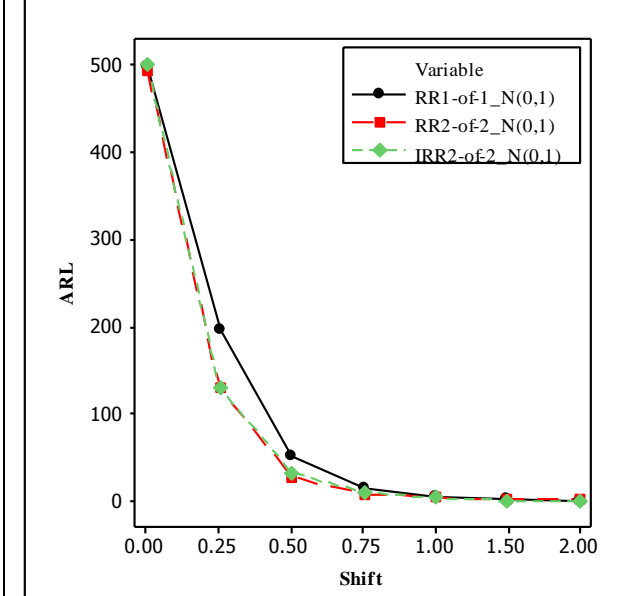

Figure 3(d). Performance comparison of the $\mathrm{RR}_{1-o f-1}, \mathrm{RR}_{2-o f-2}$ and $\mathrm{IRR}_{2-o f-2} \mathrm{MW}$ charts under the standard normal distribution for $m=500$ and $n=5$.

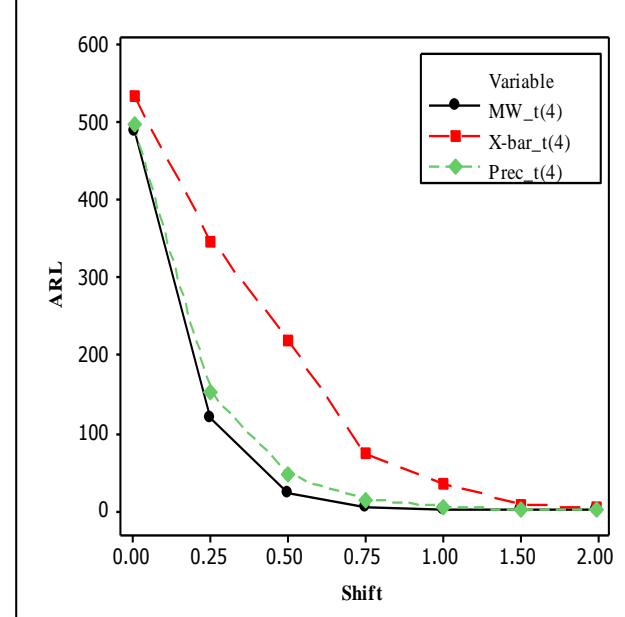

Figure 3(b). ARL versus shift for the $\mathrm{IRR}_{2-o f-2}$ Shewhart $\bar{X}$, precedence and MW charts under the $\operatorname{GAM}(1,1)$ distribution for $m=500$ and $n=5$.

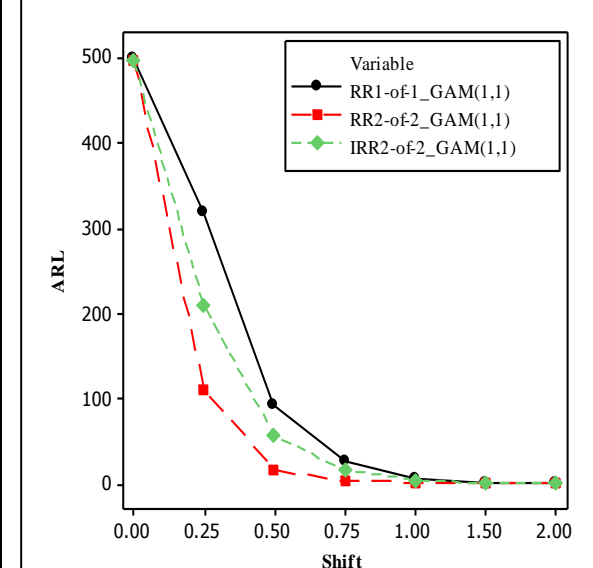

Figure 3(e). Performance comparison of the $\mathrm{RR}_{1-o f-1}, \mathrm{RR}_{2-o f-2}$ and $\mathrm{IRR}_{2-o f-2} \mathrm{MW}$ charts under the $\operatorname{GAM}(1,1)$ distribution for $m=500$ and $n=5$.

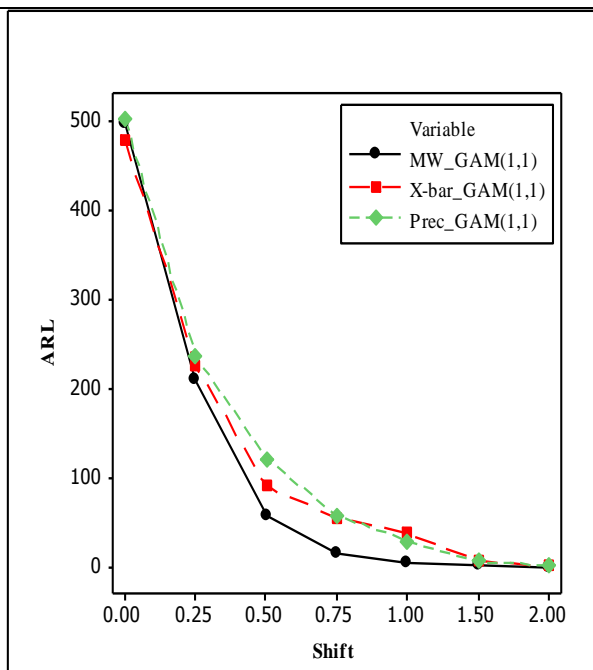

Figure 3(c). ARL versus shift for the $\mathrm{IRR}_{2-o f-2}$ Shewhart $\bar{X}$, precedence and MW charts under the $t(4)$ distribution for $m$ $=500$ and $n=5$.

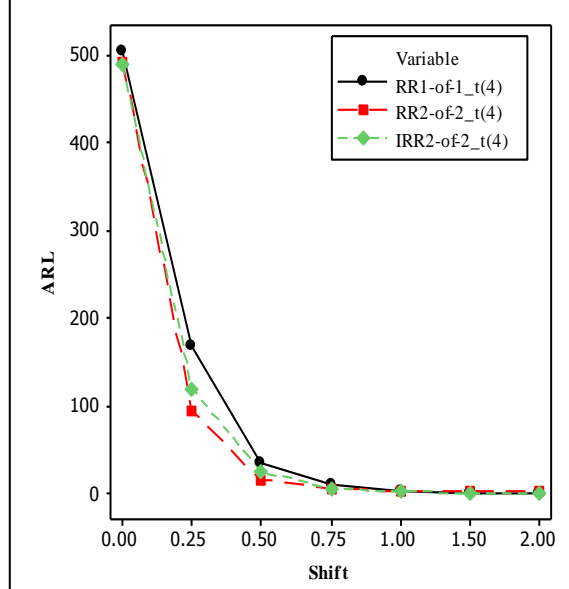

Figure 3(f). Performance comparison of the $\mathrm{RR}_{1-\text { of- }}, \mathrm{RR}_{2-o f-2}$ and $\mathrm{IRR}_{2-o f-2} \mathrm{MW}$ charts under the $t(4)$ distribution for $m=$ 500 and $n=5$. 


\section{Illustrative example}

We illustrate the implementation of the proposed distribution-free charts using a well-known dataset from Montgomery [22; page 223; Tables 5.2 and 5.3]. The data are the inside diameters of piston rings manufactured by a forging process. The data given in Table 5.2 contains fifteen prospective (Phase II) samples, each of size $n=5$. Table 5.3 contains 125 retrospective or Phase I observations, that were collected when the process was considered IC $(m=125)$. These data are considered to be the Phase I reference data for which a goodness of fit test for normality is not rejected.

For the $\mathrm{RR}_{1-o f-1}$ Shewhart MW chart, for an $A R L_{0} \approx 500$, the lower and upper control limits are given by 80 and 545, respectively, which yield an $A R L_{0}$ of 492.68. A plot of the MW charting statistics is shown in Figure 4. It is seen that the $\mathrm{RR}_{1-\text { off- }}$ Shewhart MW chart signals for the first time on the $12^{\text {th }}$ sample in the prospective phase.

For the $\mathrm{RR}_{2-o f-2}$ Shewhart MW chart, for a nominal $A R L_{0}$ of 500, we find $L C L_{2}=160$ and $U C L_{2}=465$ which yields an $A R L_{0}$ of 499.92. A plot of the MW charting statistics is shown in Figure 4. It is seen that the $\mathrm{RR}_{2-o f-2}$ Shewhart MW chart signals for the first time on the $9^{\text {th }}$ sample in the prospective phase. Thus, the $\mathrm{RR}_{2-o f-2}$ scheme performs better than the $\mathrm{RR}_{1-o f-1}$ scheme.

Using the same dataset Malela-Majika et al. [16] showed that the Min chart signals on the $13^{\text {th }}$ sample in the retrospective phase, whereas the precedence chart based on the median signals on the $9^{\text {th }}$ sample in the prospective phase. This confirms again that the $\mathrm{RR}_{2-o f-2}$ Shewhart MW chart performs better than its competitors for these data.

For the IRR $\mathrm{IRof-2}_{2}$ Shewhart MW chart, for a nominal $A R L_{0}$ of 500, we find $L C L_{3}=80, L W L_{3}=$ 160, $U W L_{3}=465$ and $U C L_{3}=545$ which yields an $A R L_{0}$ of 497.81. A plot of the MW charting statistics is shown in Figure 4. It is seen that the IRR 2-of-2 $_{2}$ Shewhart MW chart signals for the first time on the $9^{\text {th }}$ sample in the prospective phase. Thus, the $\mathrm{IRR}_{2-o f-2}$ and the $\mathrm{RR}_{2-o f-2}$ schemes perform better than the $\mathrm{RR}_{1-o f-1}$ scheme. 


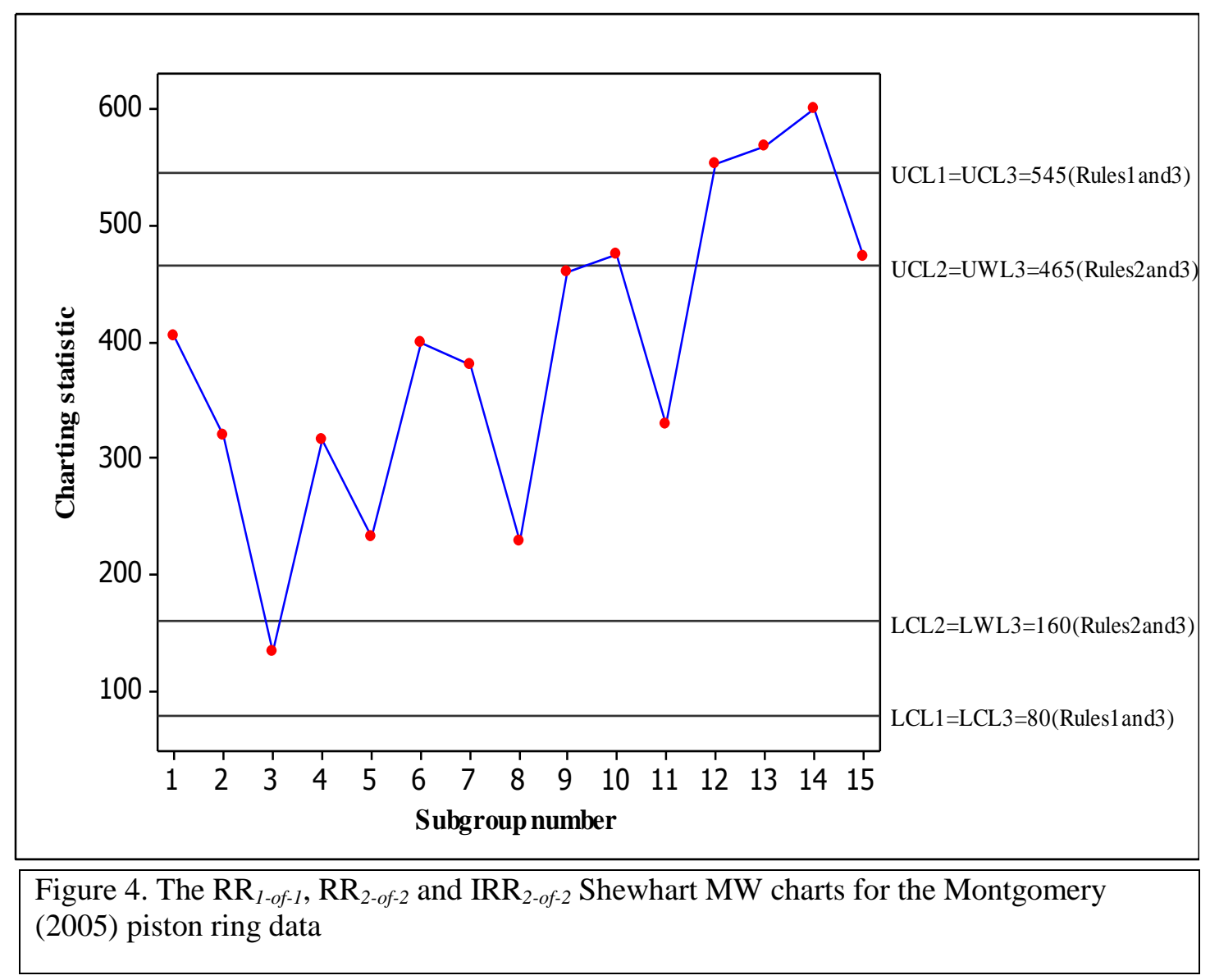

\section{Conclusion and remarks}

In this paper, we consider enhancing the performance of the Phase II Shewhart-type distributionfree chart based on the well-known Mann-Whitney statistic the Shewhart MW chart, considered by Chakraborti and Van de Wiel [1], by adding standard and improved runs-rules. A performance comparison of the runs-rules enhanced Shewhart MW charts with the existing parametric and nonparametric Shewhart-type charts shows that the enhanced charts perform better in detecting shifts under distributions of various shapes. Thus, on the basis of practicality, minimal assumptions, robustness of the in-control run-length distribution and out-of-control performance, the runs-rules enhanced Shewhart MW charts are strong contenders in practical SPC applications. Note that, the focus in this article has been on the standard and improved runs-rules and enhancements of the Phase II Shewhart-type distribution-free charts. Adaptations to the scenario, such as the modified runs-rules proposed by Antzoulakos and Rakitzis [23] are currently being investigated and will be reported in a separate paper. 


\section{Acknowledgements}

This work formed a part of the first author's Master's dissertation at the University of Pretoria and was supported by a bursary from the South African Research Chair Initiative (SARChI) funds awarded to the second author at the Department of Statistics at the University of Pretoria. The research of the third author was partly supported by a National Research Foundation grant (Reference: TTK14061168807, UID: 94102).

\section{References}

[1] Chakraborti S, Van de Wiel MA (2008) A nonparametric control chart based on the Mann-Whitney statistic. IMS Collections. Beyond Parametrics in Interdisciplinary Research: Festschrift in Honor of Professor Pranab K. Sen 1:156-172.

[2] Gibbons JD, Chakraborti S (2010) Nonparametric Statistical Inference, 5th ed., Taylor and Francis, Boca Rator, FL.

[3] Park C Reynolds Jr MR (1987) Nonparametric procedures for monitoring a location parameter based on linear placement statistics. Sequential Analysis 6(4):303-323.

[4] Zhou C, Zou C, Zhang Y, Wang Z (2009) Nonparametric control chart based on change-point model. Stat Pap 50(1):13-28.

[5] Li SY, Tang LC, Ng SH (2010) 'Nonparametric CUSUM and EWMA control charts for detecting mean shifts'. J Qual Technol 42(2):209-226.

[6] Champ CW, Woodall WH (1987) Exact results for Shewhart control charts with supplementary runs rules. Technometrics 29(4):393-399.

[7] Klein M (2000) Two alternatives to Shewhart $\bar{X}$ control chart. J Qual Technol 32: 27-431.

[8] Khoo MBC, Ariffin KN (2006) Two improved runs rules for Shewhart $\bar{X}$ control chart. Quality Engineering 18:173-178.

[9] Koutras MV, Bersimis S, Maravelakis PE (2007) Statistical process control using Shewhart control charts with supplementary runs rules. Methodology and Computing in Applied Probability 9:207-224.

[10] Chakraborti S, Eryilmaz S, Human SW (2009) A phase II nonparametric control chart based on precedence statistics with runs-type signaling rules. Comput Stat Data An 53(4):1054-1065.

[11] Zhang Y, Castagliola P (2010) Run rules $\bar{X}$ charts when process parameters are unknown. International Journal of Reliability, Quality and Safety Engineering 17(4):381-399. 
[12] Chakraborti S, Van der Laan P, Bakir ST (2001) Nonparametric control charts: An overview and some results. J Qual Technol 33(3):304-315.

[13] Chakraborti S, Graham MA (2007) Nonparametric control charts. Encyclopedia of Statistics in Quality and Reliability 1:415 - 429, John Wiley, New York.

[14] Chakraborti S, Human SW, Graham MA (2011) Nonparametric (distribution-free) quality control charts. In Handbook of Methods and Applications of Statistics: Engineering, Quality Control, and Physical Sciences. N. Balakrishnan, Ed., 298-329, John Wiley \& Sons, New York.

[15] Derman C, Ross SM (1997) Statistical Aspects of Quality Control, San Diego: Academic Press.

[16] Malela-Majika JC, Chakraborti S, Graham MA (2015) Distribution-free precedence control charts with improved runs-rules. Submitted.

[17] Barnard GA (1959) Control charts and stochastic processes. J Roy Stat Soc B 21(2):239-271.

[18] Gan FF (1994) An optimal design of cumulative sum control chart based on median run length. Commun Stat Simulat 23(2):485 - 503.

[19] Chakraborti S (2007) Run length distribution and percentiles: The Shewhart $\bar{X}$ chart with unknown parameters. Quality Engineering 19(2):119-127.

[20] Khoo MBC, Wong VH, Wu Z, Castagliola P (2011) Optimal designs of the multivariate synthetic chart for monitoring the process mean vector based on median run length. Qual Reliab Eng Int 27(8):981-997.

[21] Chakraborti S, Van der Laan P, Van de Wiel MA (2004) A class of distribution-free control charts. J Roy Stat Soc C-App, 53(3):443-462.

[22] Montgomery DC (2005) Introduction to Statistical Quality Control, $5^{\text {th }}$ Edition, John Wiley, New York, NY.

[23] Antzoulakos DL, Rakitzis AC (2008) The modified $r$ out of $m$ control chart. Commun Stat Simulat 37(2):396-408. 